\title{
EL TESORO FENICIO DE ALISEDA
}

\section{THE PHOENICIAN TREASURE OF ALISEDA}

\author{
Miguel Ángel ORTI BELMONTE \\ Correspondiente de la Real Academia de la Historia
}

\begin{abstract}
Resumen
Este trabajo fue redactado por M. Ángel Orti Belmonte (1891-1973) en los meses inmediatos al descubrimiento del Tesoro de Aliseda (Cáceres), ocurrido el 29 de febrero de 1920. Desde entonces ha permanecido inédito. Su original junto a una primera versión y otros documentos de interés para su contextualización se encuentran en la Fundación "Lucio Gil de Fagoaga" (Requena, Valencia)i. Su publicación cien años después en este Dossier enriquece la historiografía de este célebre hallazgo y sus confusas circunstancias. Asimismo, su análisis complementario ofrece una nueva lectura sobre el conflicto que mantuvieron Orti Belmonte y J. Ramón Mélida por la publicación en primicia de las joyas.

Palabras clave: Tesoro de Aliseda, Miguel Ángel Orti Belmonte, José Ramón Mélida.
\end{abstract}

\section{Abstract}

This work was written by M. Ángel Orti Belmonte (1891-1973) in the months that followed the discovery of the Aliseda Treasure (Cáceres), which occurred on February 29, 1920. Since then, it has remained unpublished. The original work a first version and other interesting documents for its contextualization are in the "Lucio Gil de Fagoaga" Foundation (Requena, Valencia). Its publication, one hundred years later in this Dossier, enriches the historiography of this famous find and its confusing circumstances. Likewise, its complementary analysis offers a new reading on the conflict between Orti Belmonte and J. Ramón Mélida over the publication of the jewels for the first time.

Key words: Treasure of Aliseda, Miguel Ángel Orti Belmonte, José Ramón Mélida.

\footnotetext{
i Archivo FLGF. Fondo “Adolfo Bonilla y San Martín”. Obra ajena y Correspondencia. Agradecemos a Álvaro Ibáñez Solaz, archivero de la citada institución, la comunicación de la existencia de estos documentos y su inestimable ayuda durante la preparación de este trabajo. Asimismo, nuestro reconocimiento a los patronos de la Fundación "Lucio Gil de Fagoaga" por permitirnos su publicación.

Quede constancia también de nuestra gratitud a Joaquín Mellado Rodríguez, autor de un reciente bosquejo biográfico sobre Orti Belmonte, y a Miguel Ángel Niño Orti, nieto de este último. Ambos atendieron con suma diligencia y una paciencia infinita nuestras frecuentes consultas.
} 
[Cuartilla] 1)

En los primeros dias del mes de Marzo ${ }^{\mathrm{ii}}$ del corriente año, encontraron unos trabajadores, en el término municipal de Aliseda, (partido judicial de Cáceres) y en el lugar conocido con el nombre de los Hornos-Tejeros, cavando para sacar arcilla los restos de una sepultura con un tesoro de incalculable valor arqueológico. Los trabajadores vinieron a Cáceres a vender las alhajas, adquiriendo parte de ellas un relojero de la localidad, pero habiendo tenido noticias del hallazgo y de la venta el Ayuntamiento de Aliseda y como propietario del terreno, denunció el hecho al Juzgado de $1^{\mathrm{a}}$ instancia de Cáceres quien se incautó de lo vendido y de lo que después encontraron los tejeros y otras personas del pueblo que desde el primer mo-...

...mento empezaron a remover el sitio del hallazgo y por último un franciscano el R. P. Acemel, entregó en el Juzgado bajo secreto de confesión el resto de las alhajas que eran las de mas valor, que habían desaparecido y alrededor de las cuales había tejido el pueblo una verdadera leyenda, de robos, y escamoteos.

Tuvimos una confidencia del hallazgo, y como enseguida se hizo público éste, intervenimos desde el primer momento como Correspondiente de la Academia de la Historia en las primeras gestiones, debiendose el afortunado éxito de las mismas en primer lugar a la Comisión de Monumentos de Cáceres y muy especialmente a los Señores $\mathrm{D}^{\mathrm{n}}$ Publio Hurtado, $\mathrm{D}^{\mathrm{n}}$ Antonio Silva, $\mathrm{D}^{\mathrm{n}}$ Gustavo Hurtado y $\mathrm{D}^{\mathrm{n}}$ Juan Sanguino, al Juez $\mathrm{D}^{\mathrm{n}}$ Vicente G Tenreiro, al farmacéutico...

... $\mathrm{D}^{\mathrm{n}}$ Jacinto Acedo, alma de la denuncia al Juzgado, al inspector de Policía $\mathrm{D}^{\mathrm{n}}$ Florentino Gomez y los agentes a sus ordenes, autores materiales del rescate. Con objeto de formar ambiente en los trabajos judiciales y robustecer nuestro juicio publicado en la prensa local, donde describimos y clasificamos los objetos se requirió al $\mathrm{Sr}$ Mélida, que se encontraba en Mérida, quien llegó a la capital cuando las alhajas estaban rescatadas y confirmo nuestra opinión y la del Sr Sanguino.

Este es el resumen de como aconteció el hallazgo, pasando por alto los amargos dias que paso la Comisión de Monumentos, viendo el peligro que corrían de emigrar al Extranjero las joyas encontradas y como varios de sus miembros tomamos parte...

\footnotetext{
ii Probablemente se trate de la fecha en que Orti tuvo conocimiento del hallazgo, que sucedió el 29 de febrero de 1920.
} 
....amistosamente en las actuaciones judiciales haciendo ver el valor artístico que tienen y que la propiedad de las mismas era del Estado y celebrando una larga sesión donde disertamos varios de sus miembros sobre las joyas, remitiendose despues copia del acta a las Reales Academias de la Historia y San Fernando a quienes se dio cuenta del hallazgo.

Llevaron a lavar los objetos encontrados a una charco cercano, donde se deterioraron y rompieron algunos al frotarlos, las piedras y pastas vitreas saltaban y se deshacían segun aseguran y despues de pasar por distintas manos han sufrido sensibles roturas. El encuentro de las alhajas ha sido puramente casual, por lo que desde el primer momento y para...

...siempre, hay que descartar la menor sospecha de falsificación moderna de que tan llenos están los anales de la Arqueología. Hacemos esta advertencia convencidos de que el tesoro de Aliseda ha de tener en el arte ibérico un valor tan grande como el busto de Elche y las estatuas del Cerro de los Santos.

La antiguedad de Aliseda se pierde, segun frase gráfica de los historiadores en la noche de los tiempos; sus alrededores fueron poblados por el hombre prehistórico, como lo prueban los dólmenes del pueblo vecino de Valencia de Alcántara. Unas ruinas las de Cabeza-Rabbi, fueron juzgadas como romanas por el Marqués de Monsalud, ${ }^{(1)}$ e Historia-

(1) B.A.H. Año 1903. Nuevas lápidas romanas de Extremadura.

...dores regionales identifican la Aliseda con la Isaelecus o Sallaecus romana citada por Ptolomeo en su Carta geográfica.

En nuestro viaje a Aliseda visitamos Cabeza-Rabbi que es la ladera de una de las montañas, en donde hemos visto nueve sepulturas labradas a flor de tierra, en la misma roca, y en perfecto estado de conservación. Miden 1'90 metro de largo, por 0 '50, de ancho en los pies y un poco mas de anchura lo correspondiente a la cabeza, como en los sarcófagos orientales. No conserva ninguna tapa y el interior, por lo tanto, esta lleno de tierra y agua; el sitio de la cabeza labrado en redondo y formando una almohadilla para levantarla, presentando una cavidad en el... 
...en el [sic] ensanchamiento de los hombros. Todos los alrededores estan sembrados de cascotes de ladrillos rojos, muy groseros y con rebordes y de lanchas de pizarra, (el terreno no es pizarroso) son los restos de otras sepulturas completamente destruidas. A unos doscientos metros, en un págo llamado de las viñas y como a un metro de profundidad, una noche varios vecinos (antes del hallazgo soñaban los campesinos del pueblo con tesoros) a escondidas, fueron a cavar en la viña y encontraron tres grandes sillares de piedra; el que ha quedado desenterrado tiene labrado en hueco toscamente una pierna humana. Bien pueden ser estos sillares y un fuste de columna que se encuentra en una casa en Aliseda los restos de un templo y Cabeza Rabbi una importante necrópolis lusitana.

A un kilómetro de Aliseda, hay una mina de hierro llamada la Abundancia con dos cuevas de gran profundidad, inexplorada y a tres, otra mina llamada la Plata. Si estas minas fueron explotadas por los fenicios, tendriamos explicado lógicamente la colonización fenicia en Aliseda y la presencia por lo tanto de estas maravillosas alhajas. La de la Abundancia se ha explotado algo y las cuevas no se han explorado; si se pudiera hacerlo como nos proponemos, podria aclararse este extremo, que hoy solo es una suposición nuestra, aunque cae dentro del campo de lo probable.

En unas minas de fosforita, del Cerro del Caracol, se han encontrado huesos fosilizados...

...y el docto catedrático Sr Hernandez Pacheco ha reconocido fósiles de carnivoros: una félida del tipo y tamaño del lince y otros parecen ser del Felis spelae (leon de las cavernas).

Con estos antecedentes no puede producir extrañeza el hallazgo de que nos vamos a ocupar. Se trata de una sepultura, lo prueban varias piedras labradas que la formaban encontradas con las joyas y la arcilla del terreno, donde las hay, de hombre, como anillos signatarios, y de mujer como diademas y arracadas, por lo que suponemos que en la sepultura estaban incinerados dos cadaveres de distinto sexo. El haber removido el terreno nos ha imposibilitado el poder formarnos una idea de la disposición de la sepultura.

Pasamos a reseñar los objetos, agrupados según su naturaleza ${ }^{(1)}$ 
De vidrio. Una vasija color verde claro y limpio, que salió intacta y estuvo en poder de un carpintero, despues lo rompió una niña a quien se lo dieron para jugar. Por la comparación que me han hecho, debió ser de la forma del oenochoe griego. Solo se han podido encontrar dos pedacitos del cuello, cuya boca completado el círculo, no fué mayor de unos 40; a 45 milímetros. Aparece grabada en ellos una inscripción, toda o parte de ella en caracteres jeroglificos egipcios y dos cartuchos o sellos reales con sus inscripciones, sirviendo de base un pequeño adorno a manera de plinto, como en los cartuchos del templo de Karnach: son los siguientes:

(1) El estudio de las joyas, lo hicimos muy deprisa en el Juzgado, pues se depositaron en el Banco de España, por lo que podrá tener algun error de medidas o de número nuestro trabajo.

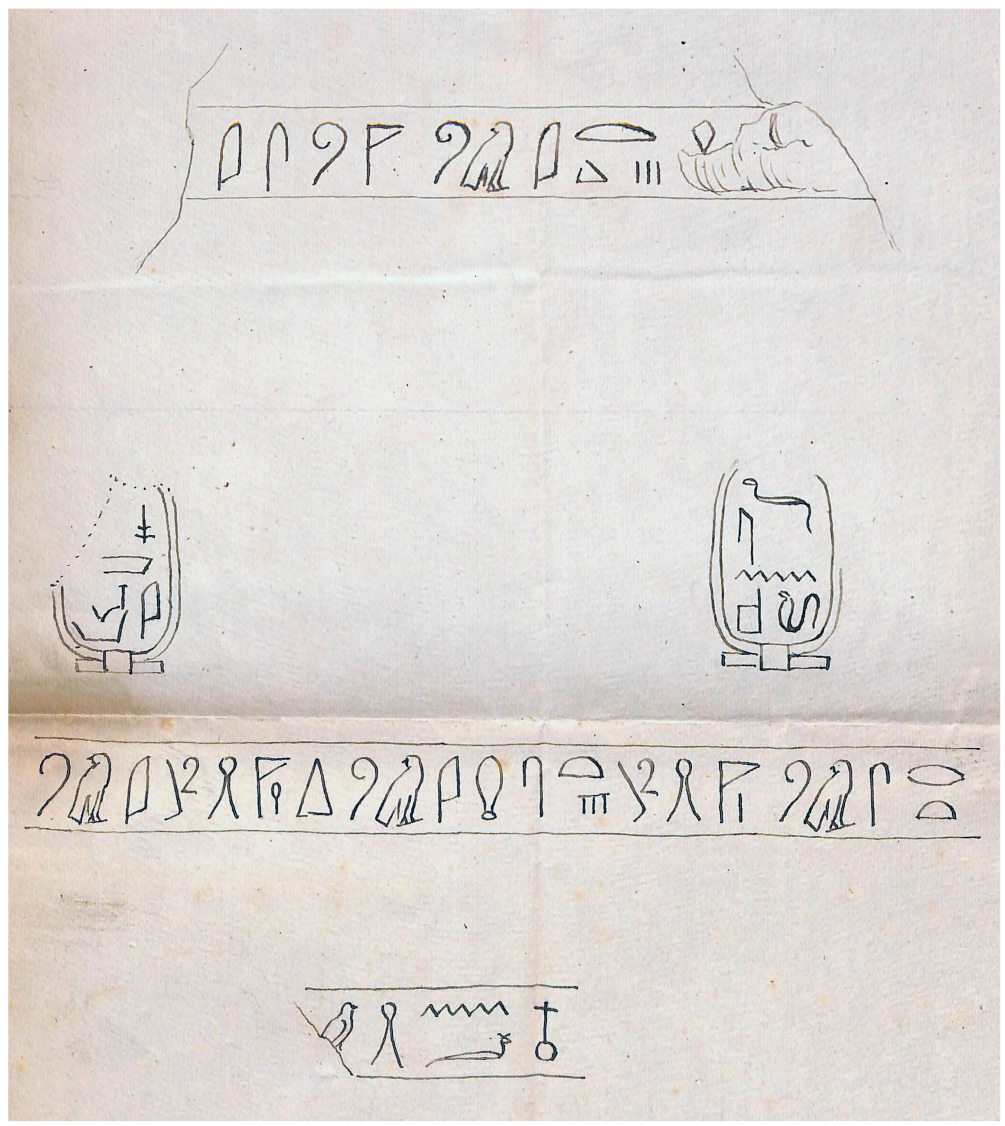

Dibujo 1. Dibujo de las inscripciones [segunda versión] 
Se determinan algunos signos de este jeroglifico con el alfabeto que incluye Maspero en su Historia Antigua de los Pueblos de Oriente. En la leyenda y numerando los signos, el 19 es la s, el 20 la r, el 12 y el 21 la t. El 1, 8 y 18, son tres pájaros con el pico vuelto, tan estilizados que no podemos señalar a qué letras corresponden del alfabeto de Champollión, sólo indicar que parecen ser del Halcón, símbolo del Dios Horus. El 6 una Delta griega, le hace falta un tracito en el centro de la base, del triángulo, aunque está interrumpida la línea, para ser letra egipcia. El 10 parece corresponder al que representa la idea de guardar [dibujo $1]$.

Lo mismo que con estos signos ocurre con otros en que les falta algún detalle para poder indicar con precisión, sin temor a exponerse a un error, a qué signo corresponde.

En el cartucho más entero está el símbolo del Nilo o del agua, con seis vértices. Con el auxilio de la lente se distingue un lagarto que es la $\mathrm{T}, \mathrm{Ts}, \mathrm{Dj}$, que debajo del signo del agua se vuelve a repetir otra vez, pero más enrroscados, por lo que podría ser la serpiente Ureus.

El segundo cartucho está muy incompleto. El pedacito de cristal más pequeño tiene 5 signos entre ellos el del agua y la W, o F, pero invertido. Comparando los demás signos con grabados de obras de egiptología se encuentran otros iguales.

De lo expuesto, fundadamente opinamos que se trata de una inscripción jeroglífica egipcia, la primera que aparece en España, y por lo tanto de una transcendencia grandísima. Lástima que no se hayan podido encontrar los otros trozos del cuello que completarían la inscripción, no obstante los trabajos que hemos hecho para buscarlos. Los signos están todos muy estilizados lo que dificulta extraordinariamente su interpretación. Esta estilización pudo tener su origen en el grabador y más si fué fenicio, pues los artistas de este pueblo simplificaron más que los propios egipcios. Los signos ideográficos son escasos. Egiptólogos de la autoridad de Maspero declaran que en el estado actual de la ciencia es imposible hallar las alteraciones que hubieron de sucederse en la escritura en el curso de los siglos. ¿Y no podrá ser esta inscripción una de las de difícil lectura por estas razones? Los egiptólogos tienen la... 
...palabra: si descifran esta inscripción quizás pueda encontrarse la clave de muchos problemas históricos hoy sin resolver, a no ser que como otras fenicias se compongan de signos puestos a capricho sin formar palabras ni representar ideas.

De cobre. Una planchita de cobre, puro o con aleación, plano, muy pulimentado, oxidado llena de cardenillo, que a nuestro juicio es un trozo de espejo.

De piedra. Una piedra pulimentada de 21' 5 centimetros de largo, por 4 de ancho y 17 milimetros de grueso, agujereada en sus extremos, del mismo tipo que los de Carmona, pero mayor, se crée que otros semejantes encontrados en otros...

...lugares servían de afiladera.

De plata. Una vasija o brasero, nombre con que la bautizaron los trabajadores por la identica forma a los braseros españoles; según un técnico de la localidad de plata, de unos 45 centimetros de diametro, muy parecido al encontrado por Bonsor en Carmona ${ }^{(1)}$ en la cañada de Ruiz Sanchez, y que se colocaba según este arqueólogo sobre el pecho del cadaver al incinerarlo. Sobre la parte inferior del reborde van fijas, pero en sentido opuesto, la una a la otra, dos manos de seis dedos, sumamente largas, terminando las muñecas en dos anillas a donde va engarza-...

(1) G. Bonsor. Les Colonies Agricoles Pre-Romaines de la vallée du Betis.

...da el asa movible, que esta rota. Distinguese del de Carmona en las manos de seis dedos y en que los extremos del asa no estan terminados en cabeza de carnero. Las manos estan unidas al reborde por cuatro clavos cuyas cabezas imitan una rosa abierta. Dos manos del mismo estilo y de forma curva que pertenecieron a un brasero o vaso fenicio, forman parte de la colección de bronces antiguos de $\mathrm{D}^{\mathrm{n}}$ Antonio Vives, adquiridos por el Estado y que a juicio del Sr Mélida son fenicias ${ }^{(1)}$.

Lo extraño de la mano de seis dedos: en dibujos de cavernas del Paleolítico Auriñaciense, se han encontrado siluetas de unas manos con dedos ampu-...

(1) R.A.B.M. año 1900. J. R. Mélida. La colección de bronces antiguos de $\mathrm{D}^{\mathrm{n}}$ Antonio Vives. 
...tados, habiendose interpretado como signos mágicos, idea que aun tienen algunos pueblos modernos y por lo tanto quizá no sea capricho del comercio púnico, estas manos de seis dedos en el brasero, sino creencia religiosa del pueblo lusitano que fué muy supersticioso, como lo prueban los cultos locales perpetuados en la Lusitania, a traves de la dominación romana.

Se encontraron, además, pedazos de plata en gran cantidad, que pertenecerían a otra vasija fundida por el fuego cuando la cremación del cadaver, pues no podemos asegurar que lo haya sido por la acción del tiempo, por ser el único objeto destrozado, aunque lo mismo que el brasero estan recubiertos de una capa obscura y co-...

...mo la plata no se oxida por el aire, pudo haberse formado esta pátina durante la incineración o por descomposición de materia orgánica.

De oro.

Un cuenco o pátera sin pie, bastante hondo, de 17,5 a 19 centímetros de diámetro sin decoración alguna. Pudo ser empleado como vaso para perfumes o afeites como el de Vermellón: no conserva señales alguna del fuego y está muy abollado. Recuerda este cuenco a las copas sin pie utilizadas para las libaciones y que los griegos llamaban fiala. Las fialas recibieron casi siempre adorno de flores de loto, pues los egipcios fueron los que idearon estos vasos de libaciones.

Un aro de oro, hueco, terminado en dos bellotitas que lo cierran y que debió de servir para el peinado: el peinado ibérico fué descrito por Artemidoro en la antigüedad y en las escavaciones de la Arcóbriga, dirigidas por el Excmo. Señor Marqués de Cerralbo se encontró una pieza de hierro en forma de collar cilíndrico, pero con una delgada placa a la altura de la nuca que se ha supuesto servía para ajustar el alto tocado de las ibéricas. Este aro no tiene plaquita, pero habiéndose hecho la prueba por su tamaño sirve perfectamente para sujetar el peinado de la mujer.

Collar. El número de piezas sueltas es grandísimo y suponemos que no todas son de esta alhaja, llegarán a unas 250 . El collar es de varias vueltas, cayendo sobre 
el pecho como vemos en las estátuas del Cerro de los Santos. Ha sido muy sensible el que las hayan desarticulado, pues nunca se podrá saber como estaban engarzadas, ya que ninguna persona técnica lo vió cuando fue encontrado. Las piezas componentes del collar son a nuestro juicio las siguientes:

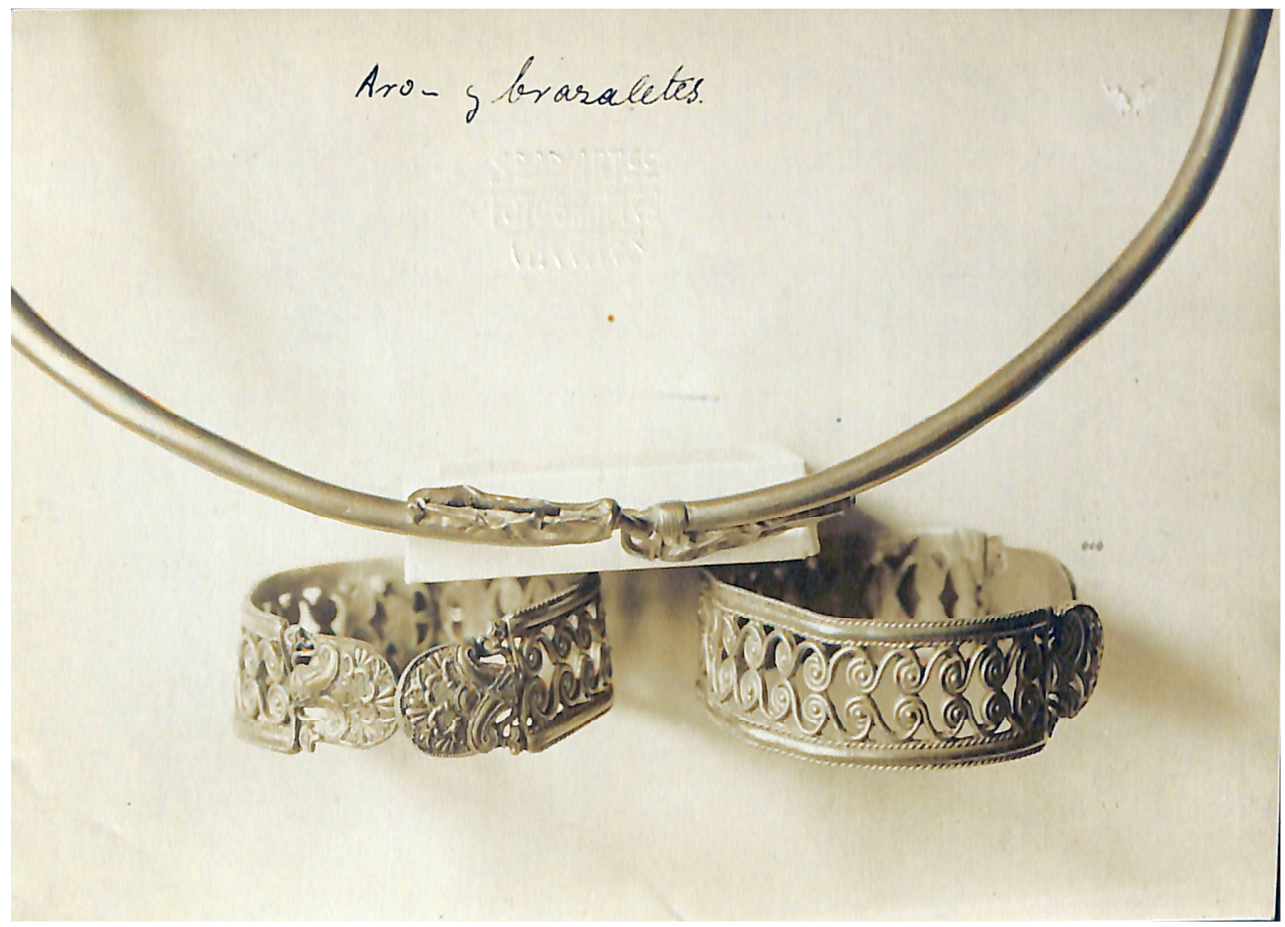

Foto 1. Aro y brazaletes

Cuentas de oro, huecas; unas redondas y otras fusiformes, pero de dos tamaños, con un ligero reborde y lisas, ninguna de vidrio. Glandes de distintos tamaños, idénticos en sus formas y casi iguales en su adorno a los del famoso busto de la Dama de Elche, un poco aplastados y con todo el contorno adornado con un pequeño rayado, están compuestos de dos piezas, la bellota y el cabecillo con asa, encajando en esta, y hueco como para contener talismanes. Los hay iguales al encontrado por Bonsor en la necrópolis de la Cruz del Negro, que es un amuleto según este autor. ${ }^{(1)}$

\footnotetext{
(1) Ob. cit. Fig $76-n^{\circ} 1$.
} 
Estuches colgantes en forma de tubo, cerrado por ambos lados, con asita tubular de suspensión, terminado en casquete esférico. Son idénticos a los encontrados en Ibiza $^{(1)}$. Hay otros dos mayores también cerrados y dos cilindritos terminados en cabeza de gavilán y el disco solar entre una media luna; iguales a los encontrado[s] en Cádiz (Punta de Vaca) y en Ibiza ${ }^{(2)}$.

Dos talismanes que imitan cabezas de lagarto o de una culebra pequeña. Los ojos están muy separados y tuvieron piedras preciosas o alguna materia vítrea; con el auxilio de la lente se ven señales recientes de haberlas saltado. La cabeza está adornada con líneas de oro granulentas, como queriendo imitar las irisaciones de la piel del lagarto. Se componen de dos piezas, la cabeza y la tapadera con su asita. El $\underline{\text { torquis de Alcalá de Chivert }}{ }^{(3)}$, tiene tres cabezas de ser-...

(1) A. Vives "La Necrópolis Cartaginesa de Ibiza, pág. 41. fig. 47

(2) A. Vives, obra citada

(3) J. R. Mélida, “Antigüedades ante-romanas de la costa de Levante.- R.A,b. y M.-1902.

...piente semejantes, con labor geométrica punteada a resaltada, como es corriente en joyas griegas y etruscas, opinando el Señor Mélida que son "púnicos desarrollados en la Edetania anteriormente a la destrucción de Sagunto".

Dos talismanes, en forma de media luna con el disco solar entre los cuernos, pero alargados, lisos, un poquito bombeados, con asita y de factura degenerada. El encontrado en Villaricos ${ }^{(1)}$ tiene labor granulenta. Siret ${ }^{(2)}$ dice de este talismán que es un símbolo esencial del pueblo fenicio.

(1) Memorias de la R. A. de la H. - Tomo 14.-Villaricos y Herrerias, por Luis Siret.

(2) Tyriens et Celtes en Espagne. B.A.H.-Tomo LIV.

Hay gran cantidad, mas de cien de hojas de palmetas, se hallan pareadas y unidas por un mismo tallo enrolado con un pequeño canutillo que les sirve de asita para poder pasar un hilo. Son identicas, aunque un poco mayores que las del arte cartaginés encontrado en Andalucia ${ }^{(1)}$. Las palmetas son uno de los motivos ornamentales que se repiten más en Oriente, especialmente en Egipto, Asiria, Fenicia, Persia y en 
la misma Grecia y en numerosas joyas etruscas. A nuestro juicio son de influencia oriental y su número nos hace lanzar la hipótesis de que no eran solamente elementos del collar sino que servian de guarnición, festoneando las plaquitas de las...

(1) A. Vives. ob. cit. Lam VIII.

...que hablamos a continuación. La reconstrucción de las alhajas aclarará este extremo. Estas palmetas tienen sus precedentes iguales en las asas del vaso de Amatonte, en las guarniciones del cofre fenicio de Palestrina, en los penachos de los caballos Asirios de un bajo relieve de Persepolis, en las joyas etruscas del Museo de Villa Giulia, es decir que es un motivo ornamental esparcido en todo el mundo del Mediterraneo.

Plaquitas. De los objetos encontrados que dejan suspenso el juicio por lo raros y dificiles de clasificar, son unas plaquitas de oro, en gran cantidad y con el mismo asunto. Representan la lucha entre un animal pues-...

...to de pie, de cabeza y boca muy grande y un hombre; es el leon asirio, o algún genio del mal de que las religiones orientales estan llenas. La manera de retorcer la cola del leon, su boca desmesurada, la indicación de la melena, y el acuse de fuerza en los miembros del hombre, recuerda los relieves asirios, si tenemos en cuenta que aquí se trata de un trabajo de repujado. Encima del rabo tiene un tallo de planta, que se divide en su parte superior en dos pequeñas volutas. Sobre las cabezas tienen algunas plaquitas, una ornamentación compuesta de tallos, uno mayor, curvo en roleo, como medio circulo, dentro del cual se encuentran otros dos mas...

...pequeños y encima, muy estilizadas hileras de palmetas, el fondo esta todo cubierto con un punteado granulado, que hace resaltar más el cuerpo desnudo del hombre y el del leon sin pelo. Los bordes superior e inferior estan agujereados en todo su largo, conservando muchas los clavitos sumamente diminutos y torcidos, como de haber estado clavados, ó enganchados. Los trozos de la diadema greco-romana de Mogón (Jaen) estan con agujeritos como estas plaquitas. Escenas de luchas tienen los marfiles fenicios de Acebuchal. 
Hay otras plaquitas mas estrechas pero del mismo largo, con un grifo, esfinge o genio alado,...

...cuerpo de cuadrupedo, alas en el tronco y cabeza de ave, semejantes a las que la supertición egipcia creía que poblaban sus desiertos limítrofes y a los que tanto abundan en la mitología Asiria, llena de estos genios alados y reproducidos frecuentemente por los fenicios. J. Martha ${ }^{(1)}$ reproduce unos grifos fenicios muy parecidos, procedentes de las guarniciones de un cofre fenicio de Palestrina.

Hay dos placas mayores, una intacta y la otra muy rota, con el mismo asunto de la lucha, pero han aumentado el tamaño repitiendo en dos zonas continuas la lucha $\mathrm{y}$ en medio una faja de tallos de planta.

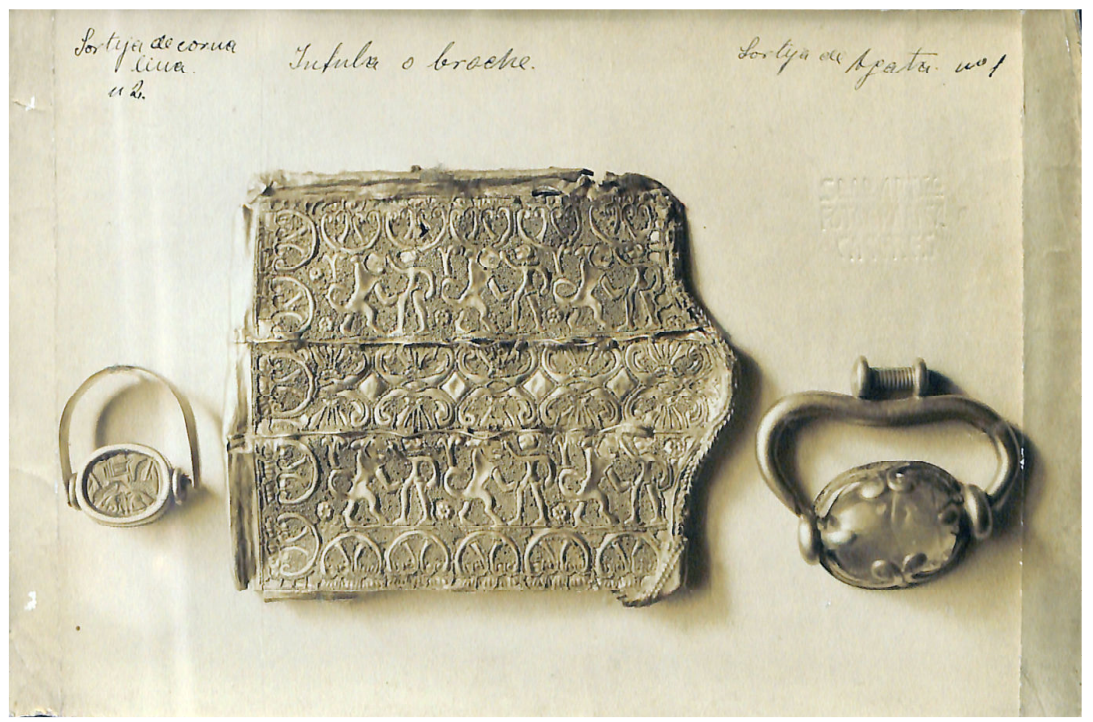

Foto 2. Ínfula o broche y sortijas de ágata y cornalina

(1) J. Martha. Archeologie etrusque et Romaine.

Dos cadenitas, como de medio metro aproximadamente, una de ellas conserva en uno de sus extremos un corchete para abrochar: uno de los hilos del trenzado de la cadena, va formando enganches, de los que podian pender los dijes glandes y talismanes. Tambien podian ir engarzadas las plaquitas, que formarian de este modo 
una cinta articulada, pero muy falsa y en el centro, a los extremos, o alternando las plaquitas de los grifos, que pudieron desempeñar lo mismo el papel de protectores del hombre en su lucha con el leon, que su enemigo, o simplemente como talismanes contra los genios maléficos.

Las placas mayores pudieron servir de infulas como vemos en las estatuas del Cerro de los...

...Santos o de hebillas de cinturon. En las sepulturas de la estacion neolítica de Los Millares (Almeria), con multitud de objetos, se han encontrado unas plaquitas de pizarra, sobre el tórax de los esqueletos, con grabados muy rudimentarios que representan una figura humana vestida. En las sepulturas micenianas y sobre los esqueletos se encontraron multitud de placas de oro.

Los brazaletes. Son dos iguales [foto 1]; un aro de oro con labor calada en el centro, en dos zonas, formadas por eses ssss tendidas y enlazadas las unas a las otras, como tallos serpenteantes: los bordes estan adornados por una media caña entre dos trenzados que imitan cordones y los extremos terminados en redondo con un repujado, compuesto, de un gran tallo o palmeta muy estilizada que se retuerce a derecha e izquierda del que arranca debajo otro tallito retorcido con gran sentimiento y terminado en una hoja: alrededor del boton del tallo mayor, se agrupan otros tres mas pequeños con triples hojas medio abiertas y en los espacios otros dos mas diminutos.

El fondo adornado de punteado granulado, asi como el tallo mayor cuya forma de enrollarse es identica a la diadema cartaginesa de $\operatorname{Tarros}^{(1)}$.

La decoración de eses se presenta de muy antiguo en las artes orientales, aparecen en cilindros eteos ${ }^{(2)}$ en el arte miceniano y en el etrusco.

En España se encuentra esta ornamentación en la espada de Almedinilla y en la diadema de la estatua del Cerro de los Santos, en el Museo Arqueológico Nacional ${ }^{(3)}$ y la decoración espiraloide muy frecuente en la cerámica ibérica.

\footnotetext{
(1) Perrot et Chipiez. tom III. Fig 603.

(2) Perrot. tom IV.

(3) Catalogada con el número 7.510.
} 
Diadema. Es bellísima y del mismo tipo que la ibérica o fenicia de Javea: se compone de tres cuerpos, el central formando un rectangulo y los otros dos que forman dos vertices triangulares. Una mano habil unió parte de las piezas sueltas de la diadema, pero no todas, por lo cual ha quedado reducida de tamaño. En su estado actual el rectangulo esta dividido en tres fajas o zonas y cada una de ocho piezas. La primera zona tiene las piececitas adornadas en su mitad al ancho y en la otra al largo por golpecitos de cordoncillo de oro, dispuestos en forma ovoidea, que quedan en hueco. La central está formada por una plaquita de oro y encima cuatro rosas tangentes las unas a las otras; los pétalos estan puestos de filo agrupa-...

...dos alrededor del boton que debió ser una piedra preciosa, pues una sola que se conserva es una turquesa. La forma de agruparse las hojas es como una especie de hélices en espiral, encontrandose cosas parecidas en la Lidia y en la Caria. La tercera zona adornada con golpes de cordoncillo, como la primera, pero solo a lo largo, esta festoneada en su parte inferior por un fleco de cuentecillas pendientes de cuatro o cinco eslabones de cadena.

Las piezas triangulares estan rodeadas por cordoncillo de oro dentro de un cajetín; en su interior cuatro círculos paralelos a la base del triangulo, que tuvieron piedras preciosas formando botones, y un motivo ornamental vegetal de tallos curvos, tambien en el vertice aparece una rosacea con bellotitas en...

...los que se admira finisima labor de repujado y una decoración de punteado que señala los nervios de los tallos y los petalos de las rosaceas. Esta forma de retorcerse los tallos en volutas se encuentra en el sarcófago fenicio de Chipre en el Museo de Nueva York. Por detras del angulo extremo de ambas piezas triangulares hay unos pasadores de los que suponemos colgaría un golpe de cuentas y hay cuatro bolitas cubiertas de adorno de filigrana hechos a buril, de una gran perfección y unidas, pues no son de una sola pieza, por clavitos interiores o por soldaduras y, aunque por su asita tubular no resultaría muy artistica la caida sobre las sienes, pudieron tener este empleo [foto 3]. 


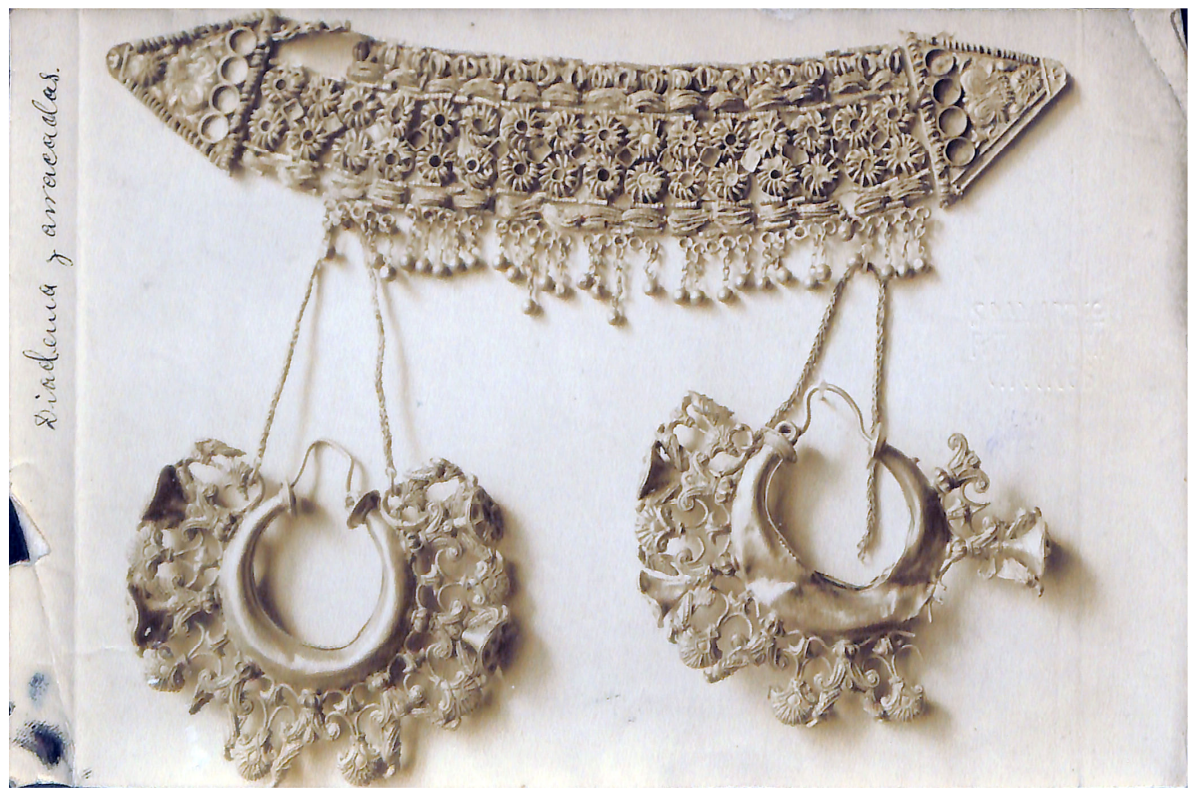

Foto 3. Diadema y arracadas

Otros dos pasadores mayores, a alguna distancia de los vertices, sirven para pasar una...

...cinta fina y sujetarla por atras a la cabeza. El estar articuladas las distintas piezas hace que se adapten muy bien a la frente y a los temporales sin molestia alguna. Hay una cinta de oro, suelta, de unos 60 centimetros de largo y 24 milimetros de ancho, sin mas decoración que cuatro líneas paralelas, a dos a dos, a todo lo largo y con dos orificios en los extremos. Los pasadores de la diadema son pequeños para que quepa esta cinta de oro, sino su aplicación no ofrecería duda, pero no obstante nos preguntamos, ¿serviria para este objeto, o es otra diadema lisa de hombre?

Brazaletes lisos del mismo caracter que esta cinta diadema se han encontrado en Portugal: los mas conocidos son, el de cerro de Monçaes [Moçaes], en la feligresia de Torgueda ${ }^{(1)}$ y los de...

(1) O Arqueologo Portugues 1904. Henrique Botelho. 
...Armozella, Lebuçao ${ }^{(1)}$. Innecesario sera decir que el arte extremeño, es Lusitano en todas sus formas, en la antiguedad. En la cueva de los Murcielagos, en Albuñol, se encontró una diadema de oro, lisa semejante a esta.

Las arracadas. Son dignas del buril de un artista ateniense y hacen parangon con la diadema [foto 3]. El cuerpo central es de forma de morcilla, liso y con broche en su terminación para el lóbulo de la oreja; a su alrededor se va agrupando la ornamentación en zonas, labradas exquisitamente con labor de filigrana y repujado; la primera formada por botones con tres hojitas indicadas con punteado de oro, cuyos dos tallitos de direcciones contrapuestas...

(1) Portugalia tomo II.

...van a unirse al ovario de una planta, que tiene un gran tallo, con sepalos como los de una flor y que se retuerce como caulículos a derecha e izquierda; encima del boton del ovario una campanilla del tipo de las plantas acuáticas que por tallos retorcidos se une a otras campanillas mas pequeñas y cerradas, como palmetas, con las que alternan, que llevan afrontadas dos aves. ¿Las flores son lotos? Muy pocos elementos de juicio tenemos para afirmarlo, porque estan muy estilizadas; pero ese empeño del orifice en hacer resaltar las tres hojitas, trae a la memoria la estilización de aquella planta en los relieves egipcios, asi como la forma de las campanillas, las escenas de caza y pesca en los estanques y...

...pantanos de Egipto.

A primera vista las aves parecen gavilanes, adorno muy característico del tocado de las reinas egipcias, y que considerado en este pueblo como simbolo de la maternidad, fué consagrado a la divinidad femenina que tiene el papel de madre en la triada egipcia, por suponerse aquellos siempre hembras y fecundadas por el viento. Un naturalista vería el buitre con su pico encorvado en su extrema mitad, el cuello delgado, indicando la cabeza de grandes plumas, la base del cuello rodeada de un collar de plumas finas, que aquí el artista ha imitado con el punteado de oro y con alas tan largas que no permiten ver la cola, dejando distinguir las grandes remeras de las... 
...plumas coberteras. El buitre considerado como ave de mal aguero entre griegos y romanos, fué también símbolo de Minerva. Las campanillas tenian su corola llena de esmaltes, de los que no se conservan ninguno: su decoracion es de punteado granuloso, tan marcado en la diadema, brazaletes y plaquitas. La arracada, ademas del broche lleva una cadena para suspenderla del pabellon de la oreja, sujeta por una anillita al roleo de los ultimos tallos, pues por su mucho peso no hay lóbulo que pueda resistirlo sin lastimarse. Un pendiente de oro liso, de los usados por el hombre, formado por un alambrito fino con dos cuentas de adorno.

No hay joya en el arte ibérico de una perfección artistica tan grande, tan armoniosa es la combinación de tallos, campanillas y tan perfecta es la técnica de repujado y filigrana.

Sortijas. Son ocho y de aspecto muy diferentes: tres con piedras, que segun técnicos, son un agata una amatista, y una cornalina: en sus caras superiores hay tallados un escarabajo, animal sagrado de los egipcios y que copiaron los fenicios: estan montadas en oro, y colocadas en casilleros que van sobre charnelas o pivotes para poder presentar las dos caras; en la inferior van grabados distintos asuntos.

La agata (número 2 de la foto 4) tiene una figurita de estilo egiptizante con un largo baston en la mano, como se representaba al Faraon o a los Dioses Ammon u Osiris.

La amatista (número [1 de la foto 2]) tiene en los extremos dos figuras de perfil, sentadas, adorando...

...un altar formado por una columnita con una cratera con el fuego sagrado, a cuyos lados hay dos genios alados y cobijando a todos el gavilan protector con sus largas alas extendidas. 


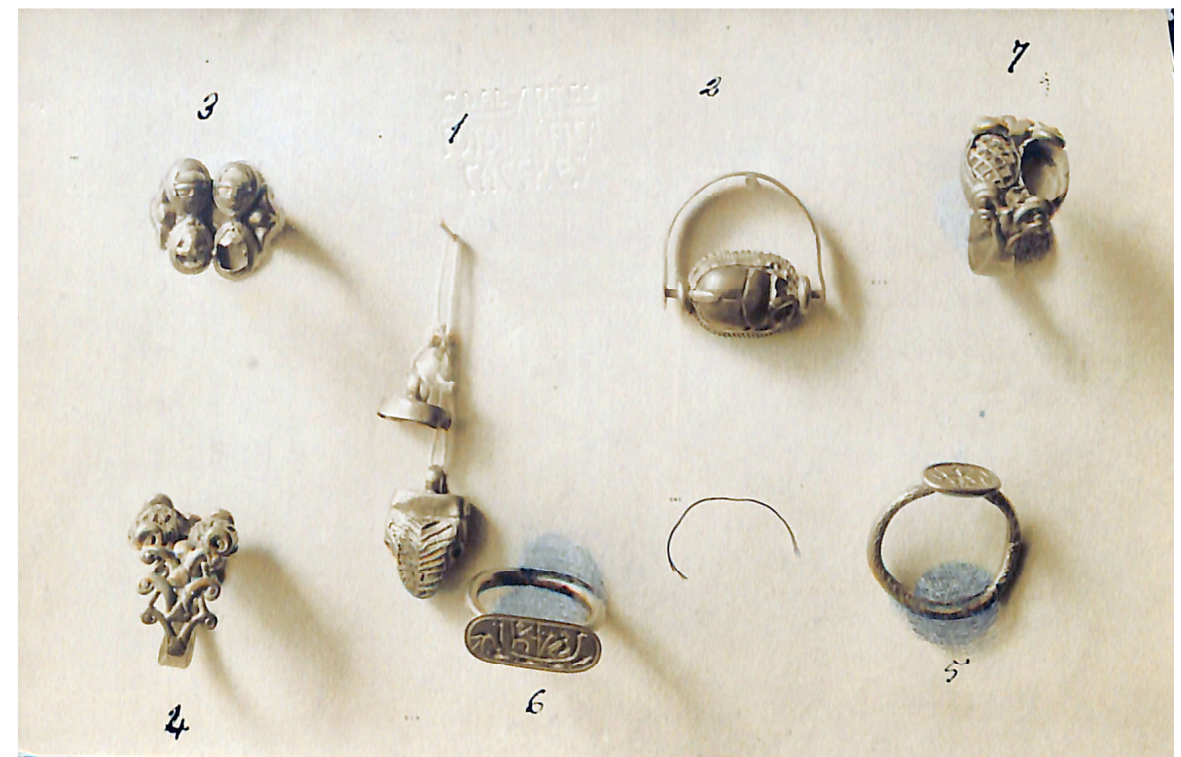

Foto 4. Sortijas. 1. Amuleto de cabeza de serpiente; 2. Sortija de piedra; 3 y 4. Sortijas del tipo de escaraboides; 5 y 6 . Sortijas de fundición; 7. Sortija con piedra de cristal.

En la cornalina (número [2 de la foto 2]) se ve una figurita sentada, tambien de perfil, del cuello le arrancan dos cabezas mirando a derecha e izquierda, tocadas con la mitra Pschent, que simbolizaba la unión del alto y bajo Egipto, distinguiendose en la parte inferior la serpiente de oro cuya cabeza se yergue delante del Pschent. Del tronco de la figurita arrancan cuatro alas como las del gavilán, propias también de los Faraones, dos casi horizontales y las otras dos dobladas hacia abajo: levanta una de sus manos enseñando la cruz anseada simbolo de la divinidad; entre las alas...

...hay tallos de planta muy estilizados, probablemente el loto. En tan pequeño espacio no falta ninguno de los atributos divinos del Faraon.

Estas sortijas son de factura fenicia y semejantes en su forma y tamaño a las encontradas en Cádiz (Punta de Vaca) y a algunas de Baleares. En Villaricos se encontró un escarabajo suelto, con el mismo asunto que la amatista, pero menos artístico. Las sortijas son de un tallado y grabado perfecto que honra como artista al pueblo que los hizo, habiendo vencido el grabador la dureza de la piedra con gran conocimiento y arte. Algo bastas son las armaduras y delante de la mayor de ellas, que es 
de las llamadas signatarias y servían de dije colgante como lo indica su asita de suspensión, cualquiera di-...

...ría que se trata de un objeto barroco.

Otras dos (nu ${ }^{\text {os }}$ [3 y 4 de la foto 4]) imitan cabezas humanas; una tiene cuatro cabecitas unidas dos a dos por las barbas: la mitad del rostro es una mascarilla de oro, formada por una laminita de oro muy fina, y la frente, pómulos y boca de pasta vitrea azul que rellena todo el interior de la mascarilla: la otra la forman dos cabecitas. De todas las alhajas, estas son las que presentan algo de iberismo, con poco arte y con algún parecido a los escaraboides y mascarillas cartaginesas y como estas quizás de caracter funerario.

Hay dos de fundición (números [ 5 y 6 de la foto 4]) con el anillo y el chaton de una sola pieza: la una tiene grabado, pero toscamente un jinete, que recuerda los de las monedas ibéricas y su aro...

...es redondo con adorno punteado; la otra es igual a las encontradas en Cerdeña y Cartago: tiene el chaton alargado en forma de cartucho, lleva grabada una barca egipcia, de las que usaban para navegar por el Nilo, terminadas la proa y la popa en cabezas de ave, con un mástil sin vela en el centro y la flor de loto donde se metia el capitan en las barcas egipcias para dirigir la embarcación: lleva dos figuritas, el remero en la actitud de sacar los remos del agua y un pasajero sentado y ademas peces y un ibis con su largo cuello removiendo el fango con el pico.

La otra sortija (número [7 de la foto 4]) es de un tipo diferente; la parte inferior del dedo es liso como un anillo, despues se abre en cuatro caulículos a cada lado como los tallos de una...

...planta, en zonas de a dos, retorcidos en sentido opuesto para coger los dos casilleros de las piedras. Una de esta la han saltado recientemente, la otra parece cristal, pues está cubierta de un esterillado de oro, formado por líneas paralelas perpendiculares las unas a las otras. Esta forma de retorcerse los caulículos dara lugar al capitel jónico con sus volutas y en estas sortijas se ve con claridad la evolución. 
El estudio de las alhajas nos mueve a las siguientes consideraciones. De todos los paralelos del mundo oriental al que con mas certeza podemos considerar como importador de este tesoro es el fenicio. Se trata pues de un tesoro púnico, ya que como dice Menendez Pelayo, es sumamente difícil "separar la arqueología fenicia de su gran colonia africana sin que a veces pueda establecerse un verdadero deslinde entre lo que peculiarmente atañe a la religión cultura artística e instituciones sociales de uno y otro pueblo".

No existen testimonios ciertos de que este pueblo dominara y colonizara de un modo permanente mas que la Andalucia Occidental hasta el Guadiana, si bien en sus periplos llegaron a las costas de Galicia y hallazgos fenicios en Portugal, como las arracadas de Castro Laundos, prueban que la colonización existió...

...en este pais. No cae pues fuera del campo de lo probable que al pasar por la grandiosa bahía de Lisboa y reconocer el estuario del Tajo, lo remontaran con sus naos y caravanas comerciando con los lusitanos se internaran tierra adentro, llegando a Isaelecus donde explotaron las minas de hierro y plata, llevando por lo tanto todo el arte fenicio a la Lusitania.

Historiadores españoles como el inolvidable maestro $\mathrm{D}^{\mathrm{n}}$ Eduardo Hinojosa, sostuvieron que los fenicios llegaron a fundar algunas ciudades en el interior. Lógicamente nos encontramos por lo tanto ante una necrópolis feno-lusitana.

Siret sostiene que los fenicios no se limitaron a fundar ciudades en la $\operatorname{costa}^{(1)}$ "sino que llegaron a dominar el Sur y Oeste de la Peninsula en donde fueron real...

(1) Tyriens et Celtes en Espagne. B.A.H. tomo LIV.

...mente los dueños. Su influencia cubre el Occidente de monumentos funerarios y se implantan profundamente sus ideas religiosas". Pero con el encuentro del tesoro de Aliseda, no se puede aceptar su teoría ${ }^{(1)}$ de que la influencia fenicia se reducia a la introducción de unos cuantos artículos de comercio insignificantes y que la gran mayoría de los productos de industria y arte, las costumbres, en una palabra la civilización y la raza enterrada en las sepulturas de la edad de hierro, eran celtibéricas genuinas, asi como tampoco en lo sucesivo seguirá suponiendose que los fenicios 
solo colonizaron la costa y que las regiones mas abiertas al comercio púnico fueron en la Península las costas de Levante.

(1) Villaricos y Herrerias. ob. cit.

Los tesoros descubiertos hasta hoy en Necrópolis ibéricas no han tenido la importancia que el actual, por su valor intrínseco y por su raro mérito artistico. Casi todos los objetos encontrados son de plata o con ligero baño de oro, en mal estado de conservación y en poca cantidad, pero nunca se han visto juntos tan gran número de palmetas, dijes, talismanes, glandes, cuentas, plaquitas, todo de oro purísimo. Extraña en el hallazgo la ausencia de cuentas de vidrio tan caracteristicas del comercio fenicio, solo hemos visto una, de cornalina, y de forma cilindrica, como tambien la falta de armas de hierro o bronce.

La influencia miceniana en España, ha sido admitida por Mélida en la diadema de Javea...

...y en las esculturas del Cerro de los Santos, el arte Egeo por Vives en los toros de Costig [Costitx] y hoy negadas por H. Schmidt y Bosch Gimpera; Pierre Paris la admite en la faja o diadema de oro de Cáceres ${ }^{(1)}$. En Portugal Leite de Vasconcellos ${ }^{(2)}$ estudió las sepulturas viendo en ellas influencias micenianas; en España el mismo tipo existe en la cueva del Romeral, según Gomez Moreno ${ }^{(3)}$ "que se repite desde Almeria al Algarbe hasta la desembocadura del Tajo". Hoy son tambien negadas estas influencias en las sepulturas españolas de cúpula...

(1) El Sr Mélida, dice que procede de Ribadeo, por lo cual no la relacionamos con el tesoro de Aliseda.

(2) O Archeologo Portugues. Junho 1902. Sepulturas prehistóricas de carácter miceniano.

(3) M. Gomez Moreno. Arquitectura Tartesia. BAH año 1905.

...por Bosch ${ }^{(1)}$ por ser muy anteriores a los micenianos, considerando completamente independiente "la evolución cultural española de los círculos culturales del Egeo". 
Leon Heuzey calificó el arte del Cerro como greco-fenicio, llamado por otros con mas propiedad greco oriental, pues con esta denominación su campo es mayor y con esta doble influencia se han encontrado objetos en la península, que es consecuencia de la expansión Mediterranea. La influencia egipcia, también existe, aunque no directamente y tan indubitable como los jeroglificos de Aliseda: las esculturas del Tajo...

${ }^{(1)}$ Hispania por Schulten y Arqueología Prerromana Hispánica por P. Bosch.

...Montero ${ }^{(1)}$ tienen marcado carácter egipcio y no citamos los hallazgos de Tarragona, ya que hay quien afirma ser de dudosa procedencia.

Hübner ${ }^{(2)}$ hizo notar comentando los marfiles descubiertos por Bonsor, en Carmona, "la mezcla singular de elementos asirios y egipcios que es la característica de los objetos del arte fenicio".

Las alhajas de Aliseda vuelve[n] a poner sobre el tapete esta influencia miceniana. Las arracadas han de ser clasificadas como greco-egipcias: la influencia del primitivo arte griego existe en ellas, y por lo tanto con la técnica etrusca, esa forma exquisita con que estan hechas la multitud de sus piececitas que encajan por ajus-...

(1) M.R. Berlanga. Descubrimientos arqueológicos verificados en el Tajo Montero. RABM año de

(2) Hübner. Objetos de comercio fenicio encontrados en Andalucía. RABM. tomo IV.

...tes remachados los unos en los otros y no por soldaduras, que no emplearon apenas los orfebres micenianos en esta clase de metal. Estan retocadas seguramente por instrumentos como el buril o el punzon; el no estar marcados con caracter propio los lotos o lirios abiertos, que en ellas figuran en forma de campanilla y la misma perfección con que estan trabajadas todas sus partes, alejan la idea de poderlas considerar como fenicias, sin aquellas influencias y mas todavia al compararlas con las medias lunas, dijes, talismanes, etc, en donde no hay arte ninguno, sino simplemente baratijas de pacotilla de un pueblo comerciante como el fenicio. Son joyas incomparables como el busto de la Dama de Elche, pero no... 
...perdidas como este para el Museo Nacional.

Las arracadas con cadena, según Maspero, aparecen en Egipto por primera vez en la dinastia XVIII. Arracadas fenicias con cadenas son las encontradas en Portugal en Castro de Laundos (Povoa de Varzin) y estudiadas por el arqueologo portugues Ricardo Severo ${ }^{(1)}$ cuyo juicio aceptamos y lo mismo en lo referente a los motivos ornamentales de los brazaletes, quien dice así. "Si desde el lejano Oriente regresamos a Fenicia, esa nación errante que se esparcio por todo el Mediterraneo, hasta las playas Occidentales del Atlantico. Nos fortalece en elementos el celebre tesoro de $\mathrm{Cu}$ rium en Chipre, una dependencia insular del pais sirio, en donde encontramos la forma penalunar con decoración espira-...

(1) Revista Portugalia 1907-pág 403

...doile y la arracada formada de la roseta o filigrana, trenza y granulado con sss, teniendo un cono suspendido de cadenas".

Chipre es el taller donde se funden las dos corrientes artisticas de Egipto y Asia Menor; la isla va perdiendo poco a poco su carácter oriental y los griegos asimilan a su arte incipiente las manifestaciones del arte chipriota.

La diadema y las arracadas debieron tener un aspecto deslumbrador, los destellos de sus esmaltes de pastas vitreas, o piedras preciosas, de las que mas de sesenta contenia la primera, y los juegos de luz y sombra del estampado y repujado de sus labores, recuerda la orfebrería miceniana, el collar y las alhajas del Bosforo Cimeriano y tantas otras obras maestras de los artistas egipcios y griegos. Si las arracadas las considerára algún arqueologo como ibéricas, tendriamos que supo-...

...ner a este pueblo con una cultura artistica y civilización muy adelantadas y no hay pruebas para afirmarlo, fuera del jinete de Palencia, de cuya autenticidad se duda. El encuentro de unas joyas, casi aisladas, sin escuela ni precedentes en la Península, no es a nuestro juicio prueba bastante, las tenemos que considerar como traidas por el comercio púnico y aseveran esta opinión las inscripciones jeroglificas. 
La comparación de los tallos de la terminación de los brazaletes, con los vertices triangulares de la diadema, y la ornamentación de las arracadas con su labor granulada, aleja para siempre la menor suposición de considerarlas como ibéricas. En su labor se observa el mismo estilo, asi como en las de las anteriores alhajas y hasta nos atrevemos a decir que proceden del mismo taller: no hay...

...nada de imitación, sino el mismo motivo ornamental aplicado a distintos objetos, habiendo sabido distinguir al artista a donde lo aplicaba.

Las plaquitas están hechas a golpe, con moldes de piedras según las fabricaban los orfebres fenicios, sirios, micenianos, etc, son de marcada influencia asiria, pero tan toscamente trabajadas que parecen eteos, aunque según nuestra opinión son fenicios: el fondo de punteado granuloso es de técnica fenicia y etrusca. Dominados los fenicios, ya por los egipcios, ya por los asirios, se limitaron a copiar sus artes, falsificándolas hasta el punto que los asirios se indignaban cuando llegaban a sus manos representaciones de sus dioses cambiadas y adulteradas por ellos.

Los talismanes son iguales a los que adornan el tercer hilo de perlas del cuello de la Dama de Elche, cuyo collar es feni-...

$60[58])$

...cio según el erudito arqueologo Salomón Reinach. Las sortijas de Aliseda son semejantes a las encontradas en Cádiz, Ibiza, Carmona, es decir fenicias sin discusión alguna.

Son las alhajas encontradas en Aliseda a nuestro juicio de fabricación asiática y hay que clasificarlas entre los tesoros de Chipre, Cnido, Troya, Cimeriano, es decir del Asia Menor, donde se instruyeron los griegos que trajeron a Europa la civilización transformada por su genio artistico, y de la fecha nada decimos las inscripciones jeroglificas podran declararlo, si son legibles, si bien por todos sus caracteres las hemos de considerar como de los siglos VI al V antes de Jesucristo.

Cáceres. Mayo 1920. Miguel Angel Orti Belmonte C:AH.[Correspondiente: Academia de la Historia] 


\section{Apéndice: Bibliografía citada por Orti}

BONSOR, G. (1899): Les colonies agricoles pre-romaines de la vallée du Betis, París.

BOSCH, P. (1920): “La Arqueología Prerromana Hispánica”, apéndice a la obra de A. Schulten Hispania (Geografía, Etnología, Historia) (traducción de P. Bosch y M. Artigas), Barcelona, pp. 135-242.

BOTELHO, H. (1904): “Archeologia de Tras-os-Montes”, O Arqueólogo Português, IX, pp. 166-170.

GÓMEZ-MORENO, M. (1905): “Arquitectura Tartesia: la necrópoli de Antequera”, Boletín de la Real Academia de la Historia, XLVII, 1905, pp. 81-132.

HÜBNER, E. (1900): “Objetos del comercio fenicio encontrados en Andalucía”, Revista de Archivos, Bibliotecas y Museos, IV, pp. 338-354.

LEITE DE VASCONCELLOS, J. (1902): “Sepulturas prehistóricas de carácter mycenense", O Arqueólogo Português, VII (6), pp. 129-134.

MARTHA, J. (1884): Manuel d'Archéologie étrusque et romaine, París.

MASPERO, G. (1886): Histoire des peuples de l'Orient, París (4 edición).

MÉLIDA, J. R. (1900): “La colección de bronces antiguos de Don Antonio Vives", Revista de Archivos, Bibliotecas y Museos, IV.

(1902): “Antigüedades ante-romanas de la costa de Levante”, Revista de Archivos, Bibliotecas y Museos, VII, pp. 164-174.

MONSALUD, M. de (1903): “Nuevas lápidas romanas de Extremadura”, Boletín de la Real Academia de la Historia, XLIII, pp. 528-535.

PERROT, G. y CHIPIEZ, Ch. (1885): Histoire de l'Art dans l'Antiquité. Tome III: Phénice-Cypre, París, 1885.

(1887): Histoire de l'Art dans l'Antiquité. Tome IV: Sardaigne, Syrie, Cappadoce, París.

RODRÍGUEZ DE BERLANGA, M. (1902): “Descubrimiento arqueológico verificado en el Tajo Montero a principios de Febrero de 1900", Separata de Revista de Archivos, Bibliotecas y Museos, 36 pp.

SCHULTEN, A. (1920): Hispania (Geografía, Etnología, Historia), Barcelona.

SEVERO, R. (1907): “O teshouro de Laundos”, Portugalia, II, pp. 403-412. 
SIRET, L. (1906): Villaricos y Herrerías. Antigüedades púnicas, romanas, visigodas y árabes. Memoria descriptiva é histórica. Memorias de la Real Academia de la Historia, XIV, Madrid,

(1909): “Tyriens et Celtes en Espagne”, Boletín de la Real Academia de la Historia, LIV, pp. 328-338.

VIVES, A. (1917): Estudio de Arqueología Cartaginesa. La Necrópoli de Ibiza, Madrid.

\title{
COMENTARIO A "EL TESORO FENICIO DE ALISEDA" DE M. Á. ORTI: CRÓNICA DE UNA PRIMICIA FRUSTRADA
}

\author{
Las cosas podían haber sucedido de cualquier otra manera \\ y, sin embargo, sucedieron así. \\ El camino, Miguel Delibes (1920-2010)
}

El trabajo de Miguel Ángel Orti Belmonte "El tesoro fenicio de Aliseda", rubricado en Cáceres en mayo de 1920, era una de las piezas todavía extraviadas del puzle de la historia de su descubrimiento. La fortuna una vez más, propiciada en esta ocasión por la agudeza y generosidad de Álvaro Ibáñez Solaz, archivero de la Fundación "Lucio Gil de Fagoaga" (Requena, Valencia), nos ha brindado la oportunidad de conocer el texto y parte de las confusas circunstancias del hallazgo, así como la pugna mantenida entre Orti y Mélida por difundir en primicia este excepcional conjunto de alhajas. Como es sabido, el Tesoro de Aliseda irrumpió en una arqueología nacional (e internacional) que se dirimía entre el anticuarismo y una emergente profesionalización, cuyas investigaciones posteriores lo consagrarían como icono de la orfebrería orientalizante del Mediterráneo occidental (Rodríguez Díaz et al., 2014: 173-223). Pero el texto de Orti no formó parte de dicha historiografía al no ver la luz y, en el plano personal, se transfiguró con el tiempo en una suerte de "primicia frustrada" que marcó buena parte de la vida de su autor. 


\section{SOBRE EL TEXTO: UN MANUSCRITO CON DOS VERSIONES}

El manuscrito reproducido se integra en un conjunto documental conformado por una versión previa del mismo, una nota complementaria, dos dibujos de los motivos egiptizantes del jarro de vidrio, cuatro fotografías del tesoro realizadas por Julián Perate ${ }^{1}$, una hoja con las referencias de las sortijas y dos cartas que Orti remitió a Adolfo Bonilla y San Martín, eminente escritor y profesor de Derecho y de Filosofía, discípulo cercano de M. Menéndez Pelayo, con un variado bagaje intelectual e impulsor de publicaciones diversas, entre ellas la Revista Crítica Hispano-Americana (1915-1921) $)^{2}$. Precisamente esta publicación constata una relación previa entre Bonilla y Orti, donde este dio a conocer en 1917 un meritorio trabajo titulado "Nuevas Notas al Fuero de Córdoba" 3 y donde previsiblemente pretendía repetir con el estudio de las joyas de Aliseda tras descartar otras opciones. No obstante, es probable que Orti y Bonilla se conocieran de antes, ya que coincidieron en la Facultad de Filosofía y Letras de la Universidad Central de Madrid; el primero como estudiante de Historia, donde fue pupilo de José Ramón Mélida y se graduó con sobresaliente en octubre de 1913 y, más tarde, se doctoró con premio extraordinario en 1923 (Me1lado, 2018: 198-199 y 210); y el segundo como catedrático de Historia de la Filosofía desde 1905 y luego decano de dicha Facultad hasta su fallecimiento en $1926(\mathrm{Pu}-$ yol, 1927: 84) ${ }^{4}$.

El análisis de la documentación conservada en la Fundación "Lucio Gil de Fagoaga" nos ha permitido diferenciar al menos cuatro envíos de Orti a Bonilla entre mayo-junio de 1920 y septiembre de 1921. Con el primero de ellos relacionamos una versión inicial de "El tesoro fenicio de la Aliseda", mecanografiada en 39 cuartillas apaisadas con correcciones y apuntes diversos, firmada por Orti en mayo de 1920 como correspondiente de la Real Academia de la Historia; un dibujo de los cartuchos y la inscripción seudojeroglífica del jarro de vidrio, realizado en una hoja también apaisada identificada

\footnotetext{
${ }^{1}$ Reputado fotógrafo de la época, cofundador en 1900 de la Sociedad Artística Fotográfica de Cáceres.

${ }^{2}$ La revista abordaba asuntos históricos y de actualidad sobre Literatura, Filosofia, Sociología, Política, crítica de documentos y de publicaciones. Su edición comenzó en 1915, pero solo aparecieron cinco tomos, el último de ellos con fecha de 1919-1921 (Puyol, 1927: 201-202).

${ }^{3}$ Por su extensión, este estudio, firmado en julio de 1916, fue publicado en dos partes en los núms. 3 y 4 del tomo III de la citada Revista. Posteriormente, en 1967, sería reeditado en el Boletín de la Real Academia de Córdoba, 87, pp. 5-23 (Mellado, 2018: 236).

${ }^{4}$ Asimismo, cabría referir que, desde 1911, Adolfo Bonilla era miembro de número de las academias de la Historia y de Ciencias Morales y Políticas; en 1912 se incorporó a la de Jurisprudencia y Legislación, así como a la Hispanic Society de Nueva York. En 1921 accedería a la Real Academia Española. En los portales digitales de la RAH y la RAE pueden consultarse sendos bosquejos biográficos y científicos de Adolfo Bonilla, con bibliografia incluida.
} 
con el número 7 en su esquina superior derecha, y las referidas cuatro fotografías del tesoro con anotaciones descriptivas y numéricas de las piezas referidas en el texto, complementadas en hoja aparte con la identificación de las sortijas. Lamentablemente no se conserva la carta que debió acompañar a estos documentos, lo que impide precisar la fecha de su remisión más allá de la referida rúbrica de Orti al final del original.

Muy poco después, Orti Belmonte dirigió una misiva a Bonilla fechada en Cáceres el 7 de junio de 1920 con la que le adjuntaba una nota sobre los restos arqueológicos (Cabeza Rabbi, Las Viñas), mineros y paleontológicos (Abundancia, Cerro Caracol) que había explorado poco antes en el entorno de Aliseda para incorporarla en un punto concreto del texto, que ya obraba en poder de Bonilla. Pero dicha carta revela también el despliegue de consultas sobre las alhajas aliseñas que Orti estaba realizando con el fin de mostrar y validar científicamente su estudio y, por ende, presentarlas como aval a Bonilla:

Mi querido amigo: Adjunto esta nota para que la ponga en mi trabajo en la parte donde digo que las alhajas estaban en una sepultura que seguramente no estará aislada. Son apuntes que he tomado en mi reciente viaje a la Aliseda.

El Director del departamento de Antiguedades de Museo de Londres ha confirmado por carta mi juicio sobre las alhajas fenicias de la Aliseda.

Estaré en esta capital hasta el 11 del corriente en que saldré para Almendralejo (calle de Mérida $\mathrm{n}^{\circ} 35$ ) para asuntos de familia, le avisaré después a donde marche.

Perdone tanta impertinencia de su afmo amigo.

El tercer envío de Orti a Bonilla, de fecha desconocida, incluyó la versión del texto que hemos reproducido; una reelaboración más extensa que la anterior titulada "El tesoro fenicio de Aliseda" (sin "la"), pero igualmente firmada por Orti en mayo de 1920. En total son 59 cuartillas apaisadas, en su mayoría manuscritas y seis mecanografiadas (núms. 12-13 y 19-22), con no pocas rectificaciones y borrones. Entre estos nos resulta llamativo el de la carátula con los nombres tachados, si bien legibles, de H. Schmidit (sic) y Bosch Gimpera ${ }^{5}$; autores mencionados en el manuscrito al referirse al debate sobre la influencia miceniana en la península ibérica, que "las alhajas de Aliseda volvían a poner sobre el tapete". Desconocemos si Schmidt y Bosch llegaron a ser consultados al respecto por Orti o si recibieron incluso alguna copia del texto, pero la mera presencia de sus nombres en su portadilla trasluce los contactos que este

\footnotetext{
${ }^{5}$ Sobre la relación entre Hubert Schmidt y Bosch Gimpera (e.g. Mederos, 1999; Gracia, 2011).
} 
barajaba como posibles mentores de su trabajo y, tal vez, otro mensaje velado a Bonilla ${ }^{6}$. Como hemos dicho, ignoramos la fecha en que Orti remitió a Bonilla esta segunda versión corregida y ampliada de su manuscrito, aunque manteniendo la rúbrica de mayo de 1920 del primer texto. Pese a ello, intuimos por otros documentos -que valoraremos en el siguiente apartado- que esta versión final del manuscrito llegara a manos de Bonilla entre finales de 1920 y principios de 1921.

La última comunicación Orti-Bonilla atestiguada remite al 30 de septiembre de 1921. Se trata de la carta de remisión de un nuevo dibujo de los motivos jeroglíficos del jarro de vidrio, a raíz de la recuperación de otro trozo de este. Aún esperanzado de la inminente publicación de su estudio, Orti proponía sustituir este dibujo por el enviado el año antes y expresaba su interés en corregir las pruebas de la publicación. Asimismo, transmitía a Bonilla su contrariedad por la aparición del trabajo de Mélida antes que el suyo:

Mi estimado amigo. Mi hermano me dijo que este més se publicaría mi trabajo sobre las joyas de Aliseda. Ayer llegó a mis manos otro trozo del vaso con inscripciones, que copio y le remito. repito la copia de los anteriores jeroglíficos corregidos, pero no interpretados como hace Mélida en su trabajo. Al fin publicó su trabajo antes que el mio; en lo que si tengo interés es en corregir las pruebas.

Si se puede utilizar este grabado que inutilizen (sic) el anterior de los jeroglíficos.

Le estrecha la mano su admirador.

\section{SOBRE EL CONTEXTO: EL ANTES, DURANTE Y DESPUÉS DEL MA- NUSCRITO DE ORTI}

Se podría decir que la documentación conservada en la Fundación "Lucio Gil de Fagoaga" desvela una parte sustancial de la historia del manuscrito de Orti sobre el Tesoro de Aliseda entre mayo de 1920 y septiembre de 1921; sin embargo, otras evidencias previamente recuperadas ensanchan su contexto y permiten conocer con relativo detalle su antes, durante y después. Sin embargo, justo es admitir que aún persisten lagunas documentales e interrogantes que, tal vez, el tiempo y el azar contribuyan a responder.

\footnotetext{
${ }^{6}$ No parece que tales contactos se produjeran, ya que las alusiones de Bosch al Tesoro de Aliseda en su Etnología de la Península Ibérica remiten a las aportaciones de Mélida (Bosch, 1932 [2003]: 260, nota 8).
} 


\subsection{ANTES: EL INFORME PARA LA COMISIÓN DE MONUMENTOS DE CÁCERES}

Cuando, a principios de marzo de 1920, M. Ángel Orti tuvo conocimiento a través de un alumno ${ }^{7}$ del Tesoro de Aliseda, descubierto días antes en dicha localidad cacereña a unos $30 \mathrm{~km}$ al oeste de la capital, tenía 28 años (Fig. 1A). Hacía menos de cuatro que había recalado en Cáceres para tomar posesión de la cátedra de Historia de la Escuela Normal de Maestros obtenida en las oposiciones celebradas en mayo; puesto que compatibilizaría meses después con el de ayudante numerario en el Instituto de Cáceres tras aceptarle la Subsecretaría de Instrucción Pública y Bellas Artes el traslado de la plaza que había ocupado en Córdoba (Mellado, 2018: 200-201). Integrado ya plenamente en los círculos culturales de la ciudad, encontró el ambiente idóneo donde prolongar su vocación investigadora, hasta entonces centrada en la historia y el arte de Córdoba, difundida en algunas revistas y en la prensa (Mellado, 2018: 200-201 y 234-236).

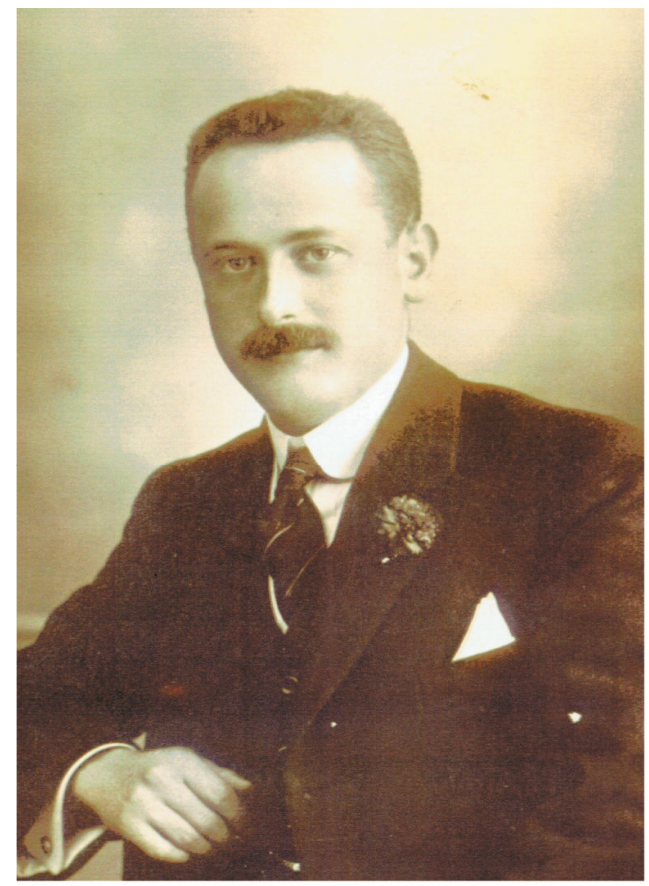

A

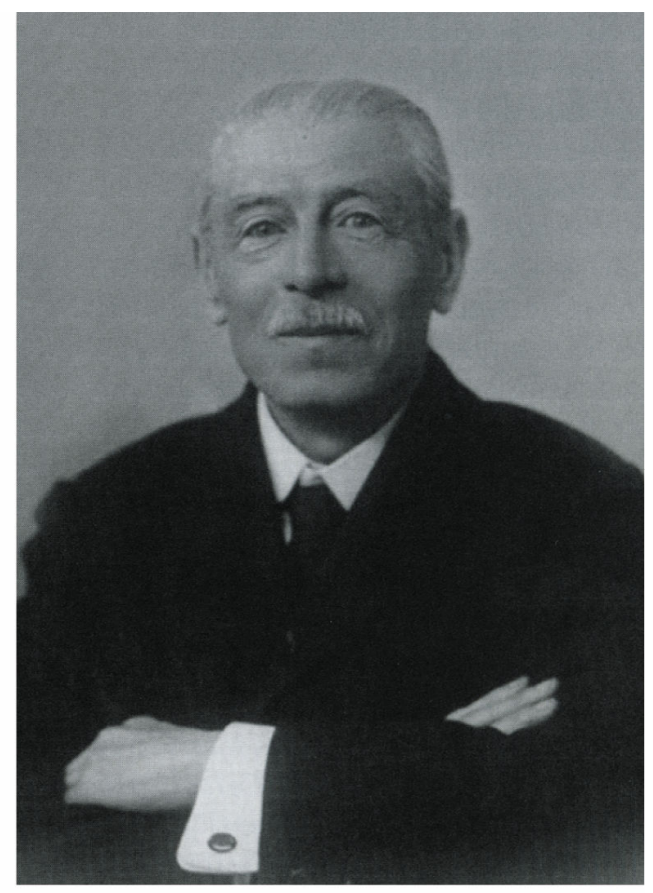

B

Figura 1. Miguel Ángel Orti Belmonte (A) y José Ramón Mélida (B)

\footnotetext{
${ }^{7}$ Según la referencia recogida por Corrales Gaitán (2004: 24), el alumno era hijo del secretario del Ayuntamiento de Aliseda, Leopoldo Zugasti Thous.
} 
Orti debió de percibir en el hallazgo de Aliseda una oportunidad inmejorable para consolidar su trayectoria científica y, tal vez, proyectarla más allá del restringido ámbito provincial en que se desenvolvía; es decir, un paso más hacia el mundo académico y hacia una emergente arqueología profesional que, no obstante, el devenir de los acontecimientos le llevaría a dar desde la Comisión Provincial de Monumentos HistóricoArtísticos de Cáceres, una institución raquítica y de lánguida existencia que viviría precisamente con el Tesoro de Aliseda la etapa más intensa de su historia (Rodríguez Díaz et al., 2014: 32-56). De hecho, la implicación de Orti en la recuperación de las alhajas junto a uno de sus vocales y a la vez director del Museo, Juan Sanguino Michel, y su aquilatada valoración de las joyas depositadas en el Juzgado tras su incautación al relojero Cezón cristalizaron en el informe que le abrió las puertas de la sobresaltada Comisión ${ }^{8}$. Aunque el original de dicho documento no se ha conservado, su contenido fue recogido y puesto en boca de Orti en el acta de la sesión de la Comisión celebrada el 14 de marzo de $1920^{9}$. Un texto prolijo en descripciones y paralelos de los jeroglíficos grabados en un incompleto y enigmático recipiente de vidrio y de unas alhajas que consideraba importadas del mundo feno-púnico o fenicio. Pero, ante las confusas noticias y las expectativas del descubrimiento aparecidas en la prensa regional los días previos, incluido el riesgo real de la salida de las piezas del país, Orti decidió también dar a conocer sus primeras valoraciones del tesoro en El Noticiero de Cáceres con el título "Informe de un técnico" ${ }^{10}$. Criterio científico frente a la especulación, orden y mesura ante el caos de "la serendipia desatada" (Ortiz, 2017). En definitiva, todo un intento de Orti por encauzar académicamente el alboroto de un hallazgo que coincidió justo en esos "amargos días" de finales de marzo con la entrega en el Juzgado de un hasta entonces desaparecido lote de joyas por el padre Acemel -confesión mediante de su retenedor- y la llegada a Cáceres de J. Ramón Mélida, apremiado telegráficamente por Publio Hurtado, presidente de la Comisión de Monumentos. Discípulo y maestro volvían a encontrarse y, en medio, el Tesoro de Aliseda.

Cuando compareció en Cáceres el 27 de marzo de 1920, Mélida contaba con 63 años y un largo currículo jalonado de altos cargos, títulos y reconocimientos: catedrático de

\footnotetext{
${ }^{8}$ Para formar parte de la Comisión era necesario ser correspondiente de una de las Academias (Orti lo era de la de la Historia), pero la norma obligaba a remitir una propuesta formal a Madrid, donde debía ser aceptada; un proceso que solía demorarse bastante. Sin embargo, el Tesoro de Aliseda hizo que la conservadora Comisión interpretara el reglamento y el mismo día 14 de marzo de 1920 diera la bienvenida a Orti y lo considerara "en lo sucesivo como individuo de esta corporación, en observancia de las disposiciones reglamentarias, lo que se participaría a las Academias" (Rodríguez Díaz et al., 2014: 160-161).

${ }^{9}$ Boletín de la Real Academia de la Historia, LXXVII, Madrid, agosto-octubre de 1920, pp. 365-379; Boletín de la Real Academia de Bellas Artes de San Fernando, 55, Madrid, 30 de septiembre de 1920, pp. 149-160.

10 "Por apremios de tiempo y original", el periódico publicó en dos veces el informe de Orti los días 27 y 29 de marzo.
} 
Arqueología en la Universidad Central, director del Museo Arqueológico Nacional, individuo de número en las Reales Academia de la Historia y San Fernando... y distinguido con la concesión de la Gran Cruz de Isabel la Católica a finales de enero de ese mismo año (Casado, 2006: 358) (Fig. 1B). Mélida conoció y calibró la entidad del tesoro al día siguiente, 28 de marzo, ya supuestamente completo y custodiado en el Juzgado. Sobre las trazas de Orti, el director del MAN emitió un breve informe cuyos párrafos finales fueron toda una declaración de intenciones y una "hoja de ruta" a seguir:

(...) Que en efecto todos los mencionados objetos son antiguos, las joyas en su mayoría fenicias, otras ibéricas, las primeras labradas casi con seguridad en Oriente e importadas por el comercio, y que todo ello, juzgando por sus caracteres, salvo error subsanable cuando estas antigüedades puedan ser sometidas al debido estudio que merecen, deberán datar del siglo VI o V antes de J.C.

Que dicho conjunto es de gran valor arqueológico, pues si bien fuera de España se han recogido y coleccionado en los Museos piezas semejantes, en nuestro país no se había presentado serie tan numerosa de joyas fenicias y púnicas, pues solamente se conocían dos series principales de las necrópolis de Cádiz y de Ibiza, más algunas piezas descubiertas en las provincias de Málaga y Sevilla; por todo lo cual es necesario que el Tesoro de la Aliseda, previo los trámites que dispone la Ley y Reglamento de Excavaciones y Antigüedades, sea objeto en Madrid de competente informe académico y quede propiedad del Estado, en beneficio de la cultura pública.

Tal es en cuanto a su leal saber y entender puede manifestar el que suscribe, remitiéndose a más detenido estudio si fuera dable realizarlo ${ }^{11}$.

Valoraciones firmes y pautas claras en términos académicos y legales que, como representante de la Ciencia, de las Academias y del Estado, Mélida hacía valer en un instante crítico del descubrimiento y justo antes de participar ese mismo día en la sesión de la Comisión de Monumentos de Cáceres, que presidió por precepto reglamentario $^{12}$. Sus intervenciones sobre el tesoro en dicha sesión fueron escuetas, pero suficientes para entrever en ellas la estrategia de "dos velocidades" delineada para gestionar el futuro inmediato de las alhajas, que al día siguiente quedarían depositadas en la sucursal cacereña del Banco de España. De este modo, la Comisión y sus miembros se ceñirían, de acuerdo con su subordinado rango institucional y sus limitadas competencias y capacidades de todo tipo, a la burocracia del asunto: traslado de actas a las Academias, recomendaciones a las autoridades para prohibir excavaciones en el lugar del

${ }^{11}$ Archivo "Victoria Mélida Ardura" (AVMA). Borrador y copia mecanografiada del informe, fechado en Cáceres a 28 de marzo de 1920.

${ }^{12}$ Boletín de la Real Academia de la Historia, LXXVII, Madrid, julio de 1920, pp. 86-92; Boletín de la Real Academia de Bellas Artes de San Fernando, 55, Madrid, 30 de septiembre de 1920, pp. 161-165. 
hallazgo hasta que la Superioridad determinase lo que procediera para esclarecer el contexto de las joyas, mantener los contactos con los informantes del descubrimiento, seguir la evolución de la causa abierta en el Juzgado, etc. Por su parte, Mélida se reservaba -sin necesidad ni obligación de expresarlo- lo sustancial y urgente: informar personalmente a las instituciones nacionales concernidas para activar el proceso legal y administrativo encaminado a que las joyas pasaran a formar del Estado lo antes posible; y, por extensión, propiciar su traslado a Madrid con el fin de someterlas al competente y detenido estudio académico que merecían.

Por su parte, la intervención de Orti fue en la misma línea de semanas atrás: complementó su primer informe con la valoración del segundo lote de joyas recuperado horas antes, que también daría a conocer en la prensa local días después. Sus palabras finales en dicho artículo, aunque con la pleitesía y respeto debidos a Mélida, traslucían un cierto tono reivindicativo que establecía orden de llegada al asunto del tesoro:

El ilustre arqueólogo señor Mélida, bien conocido de todos, ha visto las alhajas y su juicio coincide en todo con el que hemos expuesto en los tres artículos y confirma la opinión que formamos de su valor arqueológico ${ }^{13}$.

No es aventurado suponer que Mélida y Orti percibieran enseguida sus diferentes expectativas y pretensiones sobre la publicación de las alhajas más allá de sus legítimas y legitimadas actuaciones corporativas. Si el tesoro los había reencontrado, en apenas unas horas, sus posibles réditos científicos abría entre ellos una grieta de evolución incierta. Así las cosas, un Orti convencido de sus derechos y seguro de sus posibilidades asumía el reto; y, de inmediato, se aplicaría a abonar la semilla de su informe técnico con el objetivo de convertirlo en el primer fruto académico sobre el tesoro. En suma, la primicia.

\subsection{DURANTE: LA SOLEDAD INVESTIGADORA, EL DESAMPARO ACADÉ- MICO Y LA BAZA EXTRANJERA DE ORTI}

El periodo comprendido entre abril-junio de 1920 debió de ser de intenso trabajo para el tesonero Orti; una etapa de especial dedicación al manuscrito que finalmente decidió remitir a Adolfo Bonilla. Como hemos visto en la documentación de la Fundación "Lucio Gil de Fagoaga", los contactos con Bonilla revelan el envío de una primera versión del texto junto a las cuatro fotografías de Perate y el dibujo de los jeroglifos del aún incompleto recipiente de vidrio. Como añadido a dicha entrega, el 7 de

13 “Informe de un técnico III”, El Noticiero. Diario de Cáceres, 5 de abril de 1920, p. 1. 
junio remitió una nota sobre los restos del entorno de Aliseda que había visitado recientemente. No conocemos los detalles de la actividad de Orti en estas semanas, pero sospechamos que buena parte de ella la dedicara a consultar la bibliografía a su alcance, avanzada en su informe técnico y asentada en el texto en anotaciones, citas y referencias diversas a los trabajos de Maspero, Bonsor, Mélida, Vives, Siret, Martha, Perrot, Leite de Vasconcellos, Gómez-Moreno, Hübner, etc. Pero Orti debió de ser consciente enseguida de tres cuestiones esenciales: 1) la falta de medios para nutrir gráfica y bibliográficamente su trabajo de cara a perfilar sus propuestas sobre el origen, la cronología, el contexto y el marco histórico del tesoro; a saber, un conjunto excepcional de alhajas de factura fenicia o feno-púnica del siglo VI o V a.C., vinculado a una tumba doble de incineración (mujer y hombre), cuya aparición en el interior de Lusitana relacionaba con una posible proyección fenicia remontando el Tajo ligada a la metalurgia del hierro y la plata ${ }^{14} ; 2$ ) la soledad investigadora en el seno de una Comisión carente de poder ejecutivo y subordinada al mundo científico; y 3) el desamparo académico de su maestro Mélida, hombre fuerte de la Arqueología española y, desde finales de marzo, también de la gestión del tesoro en todas sus vertientes.

Tal vez fueran dichas limitaciones y dificultades las que llevaran Orti a abrir consultas y tantear otras vías posibles de publicación de su trabajo fuera de España, como las que giró al Museo Británico y al Louvre ${ }^{15}$. Contactos estos, dicho sea de paso, que mencionó solo de refilón a Bonilla en su carta de 7 de junio al apuntar el refrendo recibido del "Director del departamento de Antigüedades del Museo de Londres" sobre su valoración de las alhajas. En suma, una doble apuesta de Orti con la que pretendía mantener la ventaja sobre la primicia de las alhajas que había obtenido con la elaboración y publicación de su informe técnico. Un repaso siquiera breve a algunas de las cartas conservadas de aquellos momentos dan fe de todo ello y del calibre que alcanzó la crisis entre Orti y Mélida en la primavera-verano de 1920 y su evolución en los meses posteriores.

En paralelo, las gestiones multilaterales de Mélida en Madrid habían desembocado el 8 de junio de 1920 en la publicación en la Gaceta de la R.O. de 21 de mayo del Ministerio de Instrucción Pública y Bellas Artes que ponía proa al Tesoro de Aliseda hacia la capital del Reino. A finales de ese mismo mes, el día 27, Mélida escribió dos cartas a Sanguino Michel, una de ellas directamente relacionada con el

14 Aspectos que la historiografía posterior, ajena al estudio de Orti, ha barajado desde concepciones teóricometodológicas diversas y con un mayor nivel de conocimiento (v. apartado 3).

${ }^{15}$ Las gestiones realizadas con ambos Museos para documentar estos contactos no han reportado resultados hasta el momento. Agradecemos a Francesca Hillier (Museo Británico) y a Hélène Le Meaux (Museo del Louvre) el interés mostrado en el asunto. 
tema ${ }^{16}$. En esta le agradecía el envío de la inscripción jeroglífica del vaso de vidrio, que él también copió en su visita a Cáceres y que, con el original a la vista, podría "sacar algún partido". A continuación, Mélida mostraba su extrañeza por la falta de noticias del "amigo Orti", que no "ha enviado nada a la Academia, que acabó anteayer sus tareas". Un comentario sutil que el avisado Mélida sabía que llegaría a su destinatario; quizá porque barruntara o ya conociera el doble envite de Orti a través de Bonilla y del boticario de Aliseda, Jacinto Acedo.

Orti recibió el mensaje y no tardaría en dar señales de vida. El 18 de julio, desde Almendralejo ${ }^{17}$, le remitió a su "estimado amigo y maestro" una escueta carta en la que reconocía satisfecho sus contactos internacionales y la probabilidad de publicar en breve su trabajo en una revista extranjera, si bien todo parecía estar condicionado por la crisis del papel (Aubert, 2005); una comunicación ligada a una reivindicación legitimadora de su actuación en la salvación del tesoro, a su juicio, no reconocida aún oficialmente:

Por causa del papel no he podido todavía publicar mi trabajo sobre las joyas de la Aliseda, pero espero en breve poder publicarlo. Me he carteado respecto a las joyas con el Director del Departamento de Antiguedades del Museo Británico y con el del Louvre que me han confirmado también mi trabajo que casi con seguridad se publicará en una Revista extranjera. Vi la R.O. y me extraña mucho no haber recibido comunicado dandome las gracias, cuando Vd bien sabe que las joyas no se han perdido para España ha sido por mi intervención como estoy dispuesto a probar donde sea necesario ${ }^{18}$.

La carta de Orti debió recibir rápida respuesta por parte de Mélida que, haciendo valer su poder y autoridad académica, le "aconsejó" demorar la publicación de su estudio ante el interés no solo científico despertado por las joyas aliseñas en el extranjero; expectativas en las que, como hemos dicho, se vio envuelto incluso el farmacéutico Acedo $^{19}$. Asimismo, es muy probable que Mélida solicitara a Orti alguna aclaración sobre la copia del manuscrito remitida a Bonilla en mayo-junio ${ }^{20}$. Por desgracia, esta carta

${ }^{16}$ Archivo "Revista Extremadura" (AREX) 1071-1072, J. R. Mélida a J. Sanguino. [Ánfora griega] José Ramón Mélida. Valverde 36, 30 izqda., Madrid 27 Junio 20.

${ }^{17}$ Orti debió pasar parte del verano en esta localidad, de donde era natural su mujer, María Alcántara, con la que había contraído matrimonio el 2 de febrero de 1920 (Corrales, 2004: 14; Mellado, 2018: 201).

${ }^{18}$ AVMA, Carta de M. Ángel Orti a J. Ramón Mélida, 18 de julio de 1920.

${ }^{19}$ La única referencia a museos extranjeros en los carteos Acedo-Mélida la encontramos en una misiva muy posterior, del 26 de octubre de 1921, en la que el farmacéutico reconstruía a Mélida su conocimiento e implicación en el hallazgo: "Indignado yo, y dispuesto a que el tesoro fenicio, no fuera a enriquecer museos extranjeros..." (MAN, Expediente 1921/12.31-32).

${ }^{20}$ Desconocemos la relación que existió entre Mélida y Bonilla, pero debían coincidir con frecuencia en la Facultad y en la Academia de la Historia. Al respecto, solo hemos localizado la aportación del primero titulada "Hércules ibérico" incluida en el homenaje a Adolfo Bonilla publicado en 1930 por la Facultad de Filosofía y Letras de la Universidad Central. 
de Mélida, clave en el conflicto con Orti, no ha llegado a nuestras manos, pero la extensa contestación girada por este último el 29 de julio de 1920, de nuevo desde Almendralejo, deja entrever su contenido y grado de advertencia:

No era queja ni mucho menos lo que en mi anterior le decía, sino extrañeza de no haber recibido oficio, pues la R.O. dice que se dén las gracias a cuantas personas, entidades, etc, han intervenido. Vd dice que la Comisión de Monumentos fué la que comunicó el hallazgo y es cierto, pero eso no obsta para lo demas, pero de todos modos está bien me conformo, puesto que desaparece mi persona ante la Corporación, aunque para mi carrera hubiera sido conveniente una nota de esta índole y que las Academias especialmente la de San Fernando, lo hubiera sabido, pero me bastará contemplar las joyas en las vitrinas del Museo que Vd tan acertadamente dirige y contestarme que mucho contribuí a verlas en ese lugar.

Si alguien figurara como salvador de las joyas entonces seria cuando yo tomára la pluma y seguramente que levantaría algunas protestas como levanta siempre la verdad.

El farmacéutico de la Aliseda fue quien me enseño las cartas a que Vd alude y que son la confirmación de mi trabajo, que por otro lado para nada necesitaba por tener ya la aprobación de Vd, al acta de la Comisión y Vd querido maestro es la autoridad española en estas cuestiones como lo prueban las citas que hago de sus trabajos. Dicho Sr. contestó (al menos asi me lo aseguró) a los Museos que nada se podia vender por ser propiedad del Estado Español. Me dice Vd que en Madrid han estimado todos que por ahora lo mejor es cayar (sic) y por eso nada han publicado y ésto es precisamente lo que yo quiero evitar que nadie publique nada sin lanzar yo antes mi trabajo, pero siguiendo sus consejos demoraré la publicación y respecto al extranjero, haré lo mismo, pero yo no puedo evitar que mis tres artículos del Noticiero circulen por el mundo, lo que si le puedo asegurar es que yo no he de contribuir ni directa ni indirectamente a que se pierdan para España las alhajas de la Aliseda (...).

Mi artículo no era para el Boletín, pues con el acta de la Comisión en la que todos colaboramos era bastante para la Academia, que seguramente no hubiera publicado el acta y el trabajo juntos y yo no puedo postergar a tan buenos amigos como D. Publio y D. Juan, unido esto a la espera que tienen las cuartillas en estas Revistas pues recordará que le hablé de mi propósito de publicarlas en la de Archivos y desistí por lo que Vd me dijo en Cáceres de que se morian los trabajos en la redacción y que incluso a $\mathrm{Vd}$ le habia ocurrido con el de los dólmenes de Valencia de Alcántara.

Nada más por hoy, que las excavaciones en Numancia sean fructíferas salude en mi nombre á Blas Taracena y Vd sabe le respeta y admira su siempre discípulo y afmo amigo ${ }^{21}$.

En síntesis, Orti se plegaba a la autoridad de Mélida acatando sus "consejos" (a los efectos, órdenes) de aplazar la edición de su trabajo tanto en el extranjero como en España. Acusaba el probable aviso de que su empeño podría contribuir a que las alhajas se

${ }^{21}$ AVMA, Carta de M. Ángel Orti a J. Ramón Mélida, 29 de julio de 1920. 
perdieran para el país y corrieran la misma suerte de la Dama de Elche, con la que ya el mismo Orti había relacionado las joyas aliseñas en su informe técnico. Como contrapartida, pedía que nadie publicara el tesoro antes que él. Algo a lo que creía tener derecho por haber realizado su primera valoración y, sobre todo, considerarse salvador de las joyas; méritos que no estaba dispuesto a compartir con nadie, incluido su maestro. Asimismo, manifestaba su aspiración a ingresar en la Academia de San Fernando; deseo del que tomaría buena nota Mélida. Por último, Orti aclaraba que el texto enviado a Bonilla no era para el Boletín de la Real Academia de la Historia $a^{22}$ y hábilmente lo justificaba con la sugerencia -quizá dilatoria- que el propio Mélida le había hecho en su encuentro de finales de marzo en Cáceres. Se podría decir que Mélida había conseguido en esencia dos cosas: retener el trabajo de Orti y hacerse con el control de la vertiente científica de las alhajas.

Con el tesoro ya en el Museo Arqueológico Nacional desde últimos de septiembre de 1920 tras el sobreseimiento provisional de la causa abierta en Cáceres, Mélida se dirigió entre fines de 1920 e inicios de 1921 a Publio Hurtado, Juan Sanguino y a Orti con el mismo propósito: solicitarles informaciones diversas para el trabajo que preparaba sobre el Tesoro de Aliseda. Mélida acometía el último de los puntos clave de la "hoja de ruta" trazada en su informe del 28 de marzo de 1920. La contestación de un desarbolado Orti al director del MAN, tras valorar otros asuntos, recogía la reactivación de su publicación, materializada probablemente en el envío a Bonilla de la segunda versión del manuscrito ampliada y corregida que hemos reproducido, pero manteniendo la fecha de mayo de 1920 en la rúbrica final, así como el reproche de no haberle ayudado en su tarea:

Recibi su postal y el mismo dia vi a $\mathrm{D}^{\mathrm{n}}$ Publio y hablamos del asunto (...). Mi trabajo obra en poder del Sr Bonilla, pues Vd me pidió que demorara su publicación, créo que se publicará en breve. Yo lamento vivamente no haber obtenido facilidades para completar mi trabajo, cuando se sacaron las joyas del Banco, por su rapida marcha a Madrid. Su trabajo, aparte de la autoridad de su nombre, tendrá sobre el mío la mayor riqueza de fotografías y estudio que ha podido hacer en la mesa con los libros necesarios de que aquí carecemos. De haber obtenido su ayuda hubiera sido de otra índole y todavia ni las gracias han dado a nadie de Cáceres, cuando por nosotros (a instigación) se presentó la denuncia en el Juzgado y dimos tantos pasos para que no se perdieran las alhajas. Fui á Aliseda unos días después de $\mathrm{D}^{\mathrm{n}}$ Juan Sanguino. Siempre a sus ordenes queda su affmo amigo y discípulo ${ }^{23}$.

${ }^{22}$ Como ya dijimos, es probable que el destino del texto fuera Revista Crítica Hispano-Americana, impulsada por Bonilla.

${ }^{23}$ AVMA, Carta de M. Ángel Orti a J. R. Mélida, 12 de enero de 1921 (1920, en el original). 
Unos días después, el 21 de enero, Orti volvía a cartearse con Mélida para agradecerle la llegada de la R.O. con el reconocimiento oficial a los intervinientes en la recuperación del tesoro ${ }^{24}$. En cuanto a su trabajo, creía que estaba ya "en la Imprenta, por lo que no se si podre retirar lo de lo jeroglíficos, aunque yo solo comparo signos sin leer ni interpretar nada en los mismos" ${ }^{25}$. En mayo, Orti se dirigió de nuevo a Mélida para, entre otras cuestiones, precisarle algunos detalles sobre los restos arqueológicos y mineros del entorno de Aliseda y mostrarle su "gratitud por las molestias que se ha tomado para recomendar mi nombramiento para lo del Museo" tras la muerte de Sanguino en febrero. Pero antes de la despedida, manifestaba su inquietud por el inexplicable retraso de su publicación: "Mi trabajo aún no ha visto la luz, pues no se que pasa en la imprenta con tanto retraso" 26 .

Desconocemos el mes concreto de 1921 en que apareció el opúsculo de Mélida titulado Tesoro de Aliseda. Noticias y descripción de las joyas que lo componen, pero sabemos que el 30 de septiembre Orti reconocía a Bonilla su decepción: "Al fin publicó su trabajo antes que el mio".

\subsection{DESPUÉS: DE LA DECEPCIÓN A LA FRUSTRACIÓN}

El desencanto de Orti se haría más agudo en lo sucesivo. Por razones que ignoramos, pero imaginables, Bonilla finalmente no publicaría el estudio de Orti. Quizá por fidelidad corporativa a Mélida, por la inhibición de este último o las dificultades de Revista Crítica Hispano-Americana que ese año vería su último número, o por todo ello a la vez, el manuscrito del Tesoro de Aliseda quedaría guardado en el archivo de Bonilla. Ni su reciente ascenso a la Dirección del Museo de Cáceres, ni su posterior nombramiento como correspondiente en Cáceres de la Real Academia de Bellas Artes de San Fernando en enero de 1923, promociones ambas auspiciadas por Mélida, mitigaron a Orti el sinsabor de Aliseda. Un año después, el 2 de enero de 1924, impartiría en Córdoba la conferencia "Los fenicios y el tesoro de Aliseda", dentro de un curso organizado por la Real Academia de Ciencias, Bellas Letras y Nobles Artes de dicha ciudad. Como es fácil imaginar, la base de su discurso fueron sus aportaciones previas y el manuscrito inédito sobre el tesoro, pero sin el nervio y

${ }^{24}$ La R.O. fue publicada el 26 de enero en la Gaceta de Madrid núm. 20, p. 234. En ella se expresaba el agradecimiento por la recuperación del Tesoro de Aliseda a D. J. Ramón Mélida, al presidente de la Comisión de Monumentos de Cáceres, D. Publio Hurtado, y a los vocales de la misma D. Juan Sanguino Michel y D. M. Ángel Orti Belmonte.

${ }^{25}$ AVMA, Carta de M. Ángel Orti a J. R. Mélida, 21 de enero de 1921.

${ }^{26}$ AVMA, Carta de M. Ángel Orti a J. R. Mélida, 15 de mayo de 1921. 
los jugosos detalles del original y, sobre todo, lastrado por el desgaste de lo sucedido. Aunque sin asomo de crítica a Mélida salvo un comentario indirecto acerca del contexto de las alhajas cuestionando su relación con un escondrijo de época cartaginesa que parecía estar pergeñando su maestro, Orti no desaprovechó la ocasión para dejar constancia de su particular balance y valoración de lo acontecido hasta la fecha:

Después se han producido pleitos e incidencias, lo que ha motivado que aún no haya satisfecho el Estado, ni incluido en sus Presupuestos cantidad alguna para el pago de las alhajas a los descubridores. Triste ejemplo de la incuria de nuestra burocracia que se tendrá muy presente en Extremadura para no dar cuenta de ningún hallazgo artístico a las personas doctas, ni a las Corporaciones, al ver que pasa un año y otro y el Estado no recompensa, como es justo, a los que han descubierto tan importante tesoro, que son modestos trabajadores que viven en la mayor indigencia (Orti, 1924: 90).

Dejando a un lado los comentarios al proceder de Mélida en el asunto de Aliseda que con el tiempo fueron surgiendo en el entorno de Orti, ninguno más explícito y expresivo como el que treinta y cuatro años después del hallazgo, a cuenta de la localización del archivo del marqués de Santa Marta, salió de su propia pluma al rememorar su primicia frustrada:

Era un trabajo superior a mi salud y medios económicos el transcribir y publicar más de tres mil folios, que es la documentación encontrada, por lo que el día 1 de abril de 1951 me dirigí a D. Antonio de la Torre para que diera cuenta de mi hallazgo al Consejo de Investigaciones Científicas. Vicisitudes ajenas a la voluntad de este señor y del Consejo han dado lugar que hasta ahora no se haya hecho nada que trajera como consecuencia que este hallazgo, fruto de mi trabajo, sea aprovechado por otros, como otros se aprovecharon de que yo fuí el que salvó el tesoro de Aliseda, y dí el informe sobre el mismo que tuve la satisfacción, la única profesional, de que lo publicaran los Boletines de las Reales Academias de la Historia y de San Fernando, pero no pude conseguir publicar mi trabajo, porque había que dar prioridad al de un señor ya consagrado (Orti, 1954: 193-194, nota 1) ${ }^{27}$.

\section{VALORACIÓN HISTORIOGRÁFICA DEL MANUSCRITO DE ORTI Y ANÁLISIS DEL CONFLICTO CON MÉLIDA}

El hallazgo del Tesoro de Aliseda constituyó un verdadero desafío para el conocimiento científico y para la gestión del patrimonio arqueológico a comienzos del siglo XX. El texto inédito de Orti y las situaciones que lo envolvieron son un buen reflejo de tal coyuntura $\mathrm{y}$, por ello, merecen a nuestro juicio un análisis siquiera breve de su interés

\footnotetext{
${ }^{27}$ Agradecemos la referencia a Miguel Ángel Niño Orti.
} 
historiográfico cien años después y de los mecanismos reguladores de su conflicto con Mélida a fin de comprender el hecho de que en última instancia no viera la luz.

\subsection{EL INTERÉS HISTORIOGRÁFICO}

Como primer aspecto destacable del trabajo de Orti, debe apuntarse su afán por acreditar la autenticidad de las alhajas y, por ende, asentar la excepcional importancia del descubrimiento. Una cuestión no menor, dado el número de falsarios y falsificaciones que pululaban por el mundo del anticuarismo y las antigüedades españolas de principios del siglo XX, y con la que sin duda deben conectarse los esfuerzos invertidos en dar a conocer las circunstancias en que se produjo el hallazgo y ciertas claves que favorecieron su recuperación, relatadas al inicio de su estudio. Solo desde la claridad puesta en estos sucesos podía nacer sin mácula su segunda aportación, esto es, la reivindicación de la extraordinaria entidad de las piezas aparecidas, comparable a la Dama de Elche y la estatuaria del Cerro de los Santos.

Sobre tales bases, Orti encaró el estudio del tesoro en una doble dimensión: 1) la determinación de la filiación crono-cultural de las joyas; y 2) su contextualización arqueológica a partir de la caracterización del lugar del hallazgo, los restos y potencialidades de su entorno y su marco histórico. Un planteamiento sin duda ambicioso que, en virtud de sus posibilidades y limitaciones, resolvió satisfactoriamente en términos generales al aportar la primera valoración de este sorprendente descubrimiento y avanzar intuitivas hipótesis sobre su presencia en esta pequeña población del interior lusitano que la investigación posterior abordaría a lo largo de los años.

Un rápido recorrido por la bibliografía técnica y los paralelos arqueológicos citados en el estudio que Orti hizo de las joyas demuestra la determinación con la que, en apenas dos meses y alejado de bibliotecas especializadas y centros de investigación referenciales, abordó la procelosa tarea de transcribir la inscripción jeroglífica, asignar al tesoro una autoría fenicia o feno-púnica y situar su cronología en los siglos VI-V a.C. Aspectos todos ellos que, dicho sea de paso, asumiría en esencia Mélida en su publicación de 1921. No es nuestro objetivo recrearnos en unos pormenores que pueden fácilmente consultarse en la transcripción del documento, pero no queremos dejar pasar la ocasión para subrayar la orientación histórica con la que en este trabajo Orti trató de trascender la mera descripción de los objetos a partir de su escalada valoración contextual.

De este modo, respecto a la procedencia de las alhajas, aventuró su relación con una tumba de incineración doble, con personas de ambos sexos que podían inferirse 
de la naturaleza de algunas alhajas: anillos signatarios masculinos y diademas y arracadas femeninas. Posiblemente no haga falta recordar el importante peso de la hipótesis funeraria en la historiografía posterior, pero sí anotar cómo muchos años después algunos investigadores -como Alicia Perea (1991: 163, 2006: 52)- han llegado también a vislumbrar la doble acepción de género a la que pudieran remitir las distintas joyas.

En su empeño de ligar el tesoro con el registro arqueológico y minero-metalúrgico de su entorno, Orti recogió y exploró las evidencias conocidas del poblamiento prehistórico y antiguo en Aliseda, haciendo significativos guiños incluso a una eventual presencia foránea, inferida, sin ir más lejos, en ciertos rasgos tipológicos que acercarían las tumbas antropomorfas en piedra de Cabeza Rabbi a los "sarcófagos orientales" o la misma identificación de Aliseda con la ciudad sud-lusitana de $\mathrm{Sa}$ llaecus, que algunos autores contemporáneos asumían y de la que otros dudaban. Pero Orti se esforzó especialmente en indagar las cercanas minas de la Abundancia y la Plata y en señalar los recursos potenciales más atrayentes que la zona ofrecía para una provechosa ocupación en el pasado, insistiendo en una riqueza minera, principalmente de hierro y plata, cuya explotación protohistórica han corroborado en su vertiente férrica los estudios realizados en nuestros días (Rodríguez Díaz et al., 2015: 122-136; Pavón et al., 2017).

A mayor escala, el abordaje del marco histórico de las alhajas de Aliseda y la justificación de su presencia en tierras lusitanas llevaron a Orti a plantear una colonización fenicia vía atlántica y una ruta interior canalizada por el Tajo; una propuesta vinculada a las teorías de Eduardo Hinojosa -y, con matices, de Siret- que proponían que los fenicios llegaron a fundar algunas ciudades en el interior, no limitando su presencia a las costas. Desde tales presupuestos, Orti apostó por una presencia fenicia en Aliseda ligada a la explotación minera que conllevó una interacción con las poblaciones locales. Fruto de esta perspectiva es la calificación de "feno-lusitana" de la necrópolis que él entrevió tras el tesoro y donde puede acomodarse también su reflexión sobre los gustos lusitanos que vislumbró en las manos de seis dedos presentes en el braserillo aliseño. Como es sabido, la presencia fenicia en tierras interiores del suroeste y el occidente peninsulares siguiendo los cursos del Guadalquivir, Guadiana y Tajo sería contemplada, si bien desde nuevos registros y diversas perspectivas, por la arqueología a partir de los años noventa del siglo XX (Belén y Escacena, 1997; Pellicer, 2000; Moreno, 2001; Arruda, 2002; Vilaça y Arruda, 2004; Ferrer, 2019, etc.).

No rehuyó tampoco Orti Belmonte el debate sobre cuestiones historiográficamente candentes en su tiempo, como la presencia micénica ("miceniana") en la península ibérica, sobre la que no debemos extendernos aquí, y que, como refleja en su 
manuscrito y en las citas que contiene, dividía la opinión de los estudiosos según la valoración que hacían del registro funerario (en especial los sepulcros de falsa cúpula) y la cultura material (entre la que ciertos detalles de la diadema y arracadas de Aliseda, en el criterio de Orti, por beber en lo "miceniano", justificaban una vuelta de tuerca al problema de las tempranas conexiones con el Mediterráneo oriental). Baste decir por último que, en el frenético torbellino sobre relaciones culturales al que el estudio de paralelos arrastró a nuestro autor (como a tantos en la época y aún después), se suceden titubeantes alusiones a lo "miceniano", egeo, greco-fenicio, greco-oriental, fenicio y egipcio, justo en la antesala de un concepto -el Orientalizante- que haría aparición por esos años para integrarlas, y que se introduciría en España solo algo después, y precisamente, de la mano del Tesoro de Aliseda (Rodríguez Díaz et al., 2014: 192-193).

\subsection{ANÁLISIS Y REGULACIÓN DEL CONFLICTO ORTI-MÉLIDA}

No es fácil analizar de manera ponderada y libre de prejuicios la pugna entre Orti y Mélida por la autoría del primer estudio científico sobre el Tesoro de Aliseda. Como punto de partida, no está de más recordar que las actuaciones Mélida y Orti se desenvolvieron en el orden social e institucional que fundamentaba las relaciones jerárquicas entre las Reales Academias y las Comisiones Provinciales de Monumentos, a su vez ajustadas al marco normativo de la Ley de Excavaciones y Antigüedades de 1911 y su Reglamento de 1912. Instituciones e individuos se movían, por tanto, en dicho terreno de juego que delimitaba sus respectivos ámbitos y competencias (v. Ortiz, 2008 y Marín, 2014 para Extremadura).

En el caso de Aliseda, el veterano Mélida habitaba en el núcleo de la Ciencia, las Academias y el Estado; por su parte, el joven Orti aspiraba a través del tesoro a formar parte de la Ciencia desde la Comisión de Monumentos de Cáceres, periferia de las Academias y del Estado ${ }^{28}$. De este modo, Mélida se convirtió a partir de su llegada a Cáceres el 27 de marzo de 1920 en el garante de una gestión con tres objetivos que consideró indisociables: la urgente declaración de las alhajas propiedad del Estado a fin de evitar precedentes como el de la Dama de Elche, fortalecer al Museo Arqueológico Nacional con la incorporación de la que consideró "primera colección de su clase que se conserva en España" y, amén de sus deseos personales, el estudio científico del tesoro. Aspectos todos ellos recogidos en su informe del 28 de marzo

\footnotetext{
${ }^{28}$ Solo un vistazo a los formalismos que abrían o cerraban las cartas de los miembros de Comisión de Monumentos -y, en particular, Orti- dirigidas a Mélida revelan la distancia y la asimetría en las relaciones entre sus remitentes y el destinario: "querido maestro", "le respeta y admira", "siempre a sus órdenes", etc.
} 
como partes integradas de un engranaje en el que nunca dejó de reconocer formalmente el crucial papel jugado por la Comisión de Monumentos y el Juzgado de Cáceres en la recuperación de las joyas. Ni que decir tiene que las múltiples derivadas del hallazgo y las propias circunstancias del país, la "España de los problemas" en certera expresión de Comellas y Suárez (2003: 249), acabarían mostrando las costuras y las fallas de dicho planteamiento.

En tal estado de cosas, la Comisión de Monumentos de Cáceres asumió su papel secundario de principio a fin del proceso, como refleja toda la documentación conservada (Rodríguez Díaz et al., 2014); una posición corporativa especialmente encarnada en las figuras de Publio Hurtado, su presidente, y Juan Sanguino, vocal de la Comisión y director del Museo hasta 1921. Sin transgredir la postura oficial de la corporación a la que acababa de incorporarse, Orti consideró, no obstante, que su implicación en la salvación de las alhajas en los críticos días posteriores al descubrimiento y sus primeras valoraciones de ellas cuando aún estaban depositadas en el Juzgado le legitimaban para ser el primero en darlas a conocer a la Ciencia. Consciente del rígido marco en que se movía, abrió sus pretensiones al extranjero en paralelo (o algo antes) a su contacto con Adolfo Bonilla, rebasando los límites acotados y escenificados desde un principio por Mélida. Un auténtico órdago de Orti que, más allá de lo personal, introducía una disfunción en el sistema que devendría en conflicto; un conflicto que el sistema, Mélida mediante, se vio en la obligación de regular de forma inmediata.

Como expusiera Antonio Rodríguez de las Heras (1981) en un breve y preciso trabajo, que sus discípulos conocimos en las aulas y por el que no parece pasar el tiempo 29 , "todo sistema [de poder] dispone de siete regulaciones para asegurar que los conflictos no amenacen su estabilidad": expulsión, favor, miedo, desviación, culpabilidad, represión y sublimación. No es momento de entrar en el detalle de cada una de ellas, pero sí de aquellas que resultan más reconocibles en los carteos MélidaOrti: sublimación, miedo, culpabilidad y favor.

Según Rodríguez de las Heras, la sublimación implica introducir por quien administra el poder un elemento de reconocimiento y aceptación compartidos por las partes en conflicto: "una persona, una institución, un valor moral o cualquier ente abstracto sublimados". En nuestro caso, el indiscutible valor histórico y el alto significado de las alhajas para la Nación constituyen, a nuestro juicio, la piedra angular del argumentario sublimador de Mélida en su comparecencia en Cáceres el 28 de

${ }^{29}$ Sirva esta referencia al profesor Rodríguez de las Heras, víctima de la Covid19 en 2020, como gesto de memoria de alguien cuya huella intelectual y humana hizo -y hará- que le recordemos siempre como maestro. 
marzo de 1920 y, probablemente también, en la carta remitida a Orti en julio, si bien esta vez incorporando el temor a posibles usurpadores o compradores de las joyas; es decir, el miedo a "un antagonismo más fuerte que el existente entre el poder y la parte del conflicto". Aunque desconocemos dicha carta, la respuesta de Orti a Mélida el día 29 de ese mismo mes de julio revela el interés de los museos extranjeros en la probable adquisición de las joyas; un interés, al parecer, despachado por el boticario de Aliseda arguyendo que "nada se podia vender por ser propiedad del Estado Español". Pero junto a la sublimación y el miedo, esta misma misiva de Orti deja entrever que Mélida en la suya debió de apelar igualmente a la culpabilidad, definida en estos términos en la metodología de Rodríguez de las Heras: "El poder, en vez de presentar un culpable exterior, introduce el sentimiento de culpabilidad en la parte conflictiva". Orti expresa tal sensación muy claramente en su carta: "lo que si le puedo asegurar es que yo no he de contribuir ni directa ni indirectamente a que se pierdan para España las alhajas de la Aliseda".

Más adelante Mélida, consciente de la latencia del conflicto, introduciría el favor en su afán de afirmar el sistema y, por extensión, normalizar sus relaciones con Orti y la propia Comisión. Entendida esta regulación por Rodríguez de las Heras como "elemento de atracción y agradecimiento a la parte en conflicto”, Mélida materializó el favor en su implicación para que el Ministerio reconociera nominalmente a los principales responsables de la recuperación de las joyas, entre ellos Orti; y, de una forma aún más particular, en que este reemplazara al desaparecido Sanguino en la Dirección del Museo en 1921; y, dos años después, fuera nombrado correspondiente en Cáceres de la Real Academia de Bellas Artes de San Fernando. Se podría concluir que, a la vista de la documentación disponible, Mélida manejó el conflicto con Orti a través de acciones propias de las consideradas "regulaciones blandas y medias"; sin embargo, su silencio y su inhibición (en sí mismas, formas de acción) ante la publicación del texto de Orti en manos de Bonilla traslucen tintes de una de las medidas "duras" en el “artificio metodológico" de Rodríguez de las Heras (1983: 440): la expulsión, consistente "en negar, no tener en cuenta, minusvalorar una cuestión, un problema, un conflicto, que casi siempre se ha formulado de forma explícita". Al tiempo que se desvanecía la publicación de Orti se consumaba su alejamiento de la arqueología profesional. De hecho, en noviembre de 1921, Juan Cabré realizaría excavaciones en Aliseda en las que el papel de Orti se limitaría a facilitarle los contactos y el apoyo logístico requerido meses antes por Mélida (Rodríguez Díaz et al., 2014: 112).

Para finalizar, no podemos evitar aludir al componente emocional que destilan las palabras de Orti recogidas de sus trabajos de 1924 y 1954; dos textos sobre el Tesoro de Aliseda separados por tres décadas que sucesivamente señalaron las 
imperfecciones de la gestión del Estado y la postergación de su trabajo por la Ciencia. En una palabra, no pronunciada, Mélida. Por nuestra parte, solo hemos pretendido recuperar para la centenaria historiografía de las alhajas y para la memoria de Orti su encomiable trabajo y sus circunstancias. Pero sobre todo quisimos entender -parafraseando a Delibes- por qué las cosas sucedieron así y no de cualquier otra manera.

\author{
Alonso RODRÍGUEZ DÍAZ \\ http://orcid.org/0000-0002-4602-4337 \\ alonso@unex.es \\ Ignacio PAVÓN SOLDEVILA \\ http://orcid.org/0000-0002-6130-6463 \\ ipavon@unex.es \\ David M. DUQUE ESPINO \\ http://orcid.org/0000-0002-6045-3031 \\ despino@unex.es
}

\title{
BIBLIOGRAFÍA
}

ARRUDA, A. M. (2002): Los fenicios en Portugal. Fenicios y mundo indígena en el centro y sur de Portugal (siglos VIII-VI BC), Cuadernos de Arqueología Mediterránea, 5-6, Barcelona.

AUBERT, P. (2005): “Crisis del papel y consecuencias de la industrialización de la prensa (1902-1931), Homenaje a Jean-François Botrel, Bordeaux, pp. 73-95.

BELÉN, M. a y ESCACENA, J. L. (1997): “Testimonios religiosos de la presencia fenicia en Andalucía occidental”, Spal, 6, pp. 103-131.

BOSCH, P. (1932): Etnología de la Península Ibérica, ed. J. Cortadella, Pamplona, 2003.

CASADO, D. (2006): José Ramón Mélida (1856-1933) y la Arqueología española, Madrid.

COMELLAS, J. L. y SUÁREZ, L. (2003): Historia de los españoles, Barcelona.

CORRALES, A. (2004): D. Miguel Á. Ortí Belmonte (1891-1973). Un cacerense venido de Córdoba, Córdoba.

FERRER, E. (ed.) (2019): La ruta de las Estrímnides. Navegación y conocimiento del litoral atlántico de Iberia en la Antigüedad, Sevilla-Alcalá de Henares.

GRACIA, F. (2011): Pere Bosch Gimpera. Universidad, politica, exilio, Madrid.

MARÍN, C. (2014): Arqueología y Patrimonio Arqueológico en la Extremadura contemporánea. La Comisión de Monumentos Históricos y Artísticos de Cáceres (1898-1936), Cáceres. 
MEDEROS, A. (1999): "El joven Bosch Gimpera y la primera restructuración de la Prehistoria en España”, Boletín del Seminario de Estudios de Arte y Arqueología, 65, pp. 9-28.

MÉLIDA, J. R. (1921): Tesoro de Aliseda. Noticias y descripción de las joyas que lo componen, Madrid.

MELLADO, J. (2018): “Miguel Ángel Orti Belmonte (1891-1973), ilustre cordobés, profesor e historiador eminente", en J. M. Escobar y F. Solano (coords.): Académicos en el recuerdo 2, Córdoba, pp. 193-242.

MORENO, F. J. (2001): "Sobre variables ocultas en la Edad del Hierro de la Meseta", Actas del II Congreso de Arqueología de Toledo. La Mancha occidental y la Mesa de Ocaña, I, Toledo pp. 201-218

ORTI, M. Á. (1924): "Los fenicios y el tesoro de Aliseda", Boletín de la Real Academia de las Ciencias, Bellas Letras y Nobles Artes de Córdoba, 7, año III, enero-marzo, pp. 87-98.

(1954): “Cáceres bajo la Reina Católica y su Camarero Sancho Paredes Golfín”. Revista de Estudios Extremeños, X (1-4), pp. 193-328.

ORTIZ, P. (2008): Institucionalización y crisis de la arqueología en Extremadura. Comisión de Monumentos de Badajoz. Subcomisión de Monumentos de Mérida (1844-1971), Badajoz.

(2017): "El tesoro arqueológico o la serendipia desatada", en A. Rodríguez, I. Pavón y D. M. Duque (eds.): Historias de Tesoros, Tesoros con Historia, Cáceres, pp. 13-36.

PAVÓN, I., DUQUE, D. M., RENZI, M., ROVIRA, S. y RODRÍGUEZ, A. (2017): "El horno protohistórico de reducción directa de La Pastora (Aliseda, Cáceres)", Trabajos de Prehistoria, 74 (2), pp. 335-354.

PELLICER, M. (2000): "El proceso orientalizante en el Occidente ibérico", Huelva Arqueológica, 16, pp. 89-104.

PEREA, A. (1991): Orfebrería prerromana. Arqueología del Oro, Madrid.

(2006): "Entre la metáfora y el mito. La representación simbólica de lo femenino", $M A R Q$ Arqueología y Museos, 01, pp. 49-68.

PUYOL, J. (1927): Adolfo Bonilla y San Martín (1875 t 1926). Su vida y sus obras, Madrid. RODRÍGUEZ DE LAS HERAS, A. (1981): "Las regulaciones del conflicto”, Norba, 2, pp. 273-280.

(1983): "Cuatro discursos de Manuel Azaña", Norba, 4, pp. 437-445.

RODRÍGUEZ DÍAZ, A., ORTIZ, P., PAVÓN, I. y DUQUE, D. M. (2014): El tiempo del Tesoro de Aliseda, I. Historia e historiografía del hallazgo, Cáceres.

RODRÍGUEZ DÍAZ, A., PAVÓN, I. y DUQUE, D. (eds.) (2015): El tiempo del Tesoro de Aliseda, II. Aproximación a su contexto Arqueológico, Cáceres.

VILAÇA, R. y ARRUDA, A. M. (2004): “Ao longo do Tejo, do Bronze ao Ferro”, Conimbriga, XLIII, pp. 11-45. 